\title{
Azimuthal Distribution of Deep Convection, Environmental Factors, and Tropical Cyclone Rapid Intensification: A Perspective from HWRF Ensemble Forecasts of Hurricane Edouard (2014)
}

\author{
HUA LEIGHTON \\ NOAA/Atlantic Oceanographic and Meteorological Laboratory/Hurricane Research Division, and Cooperative Institute for Marine \\ and Atmospheric Studies, Rosenstiel School of Marine and Atmospheric Science, University of Miami, Miami, Florida \\ SUNDARARAMAN GOPALAKRISHNAN \\ NOAA/Atlantic Oceanographic and Meteorological Laboratory/Hurricane Research Division, Miami, Florida \\ JUN A. ZHANG \\ NOAA/Atlantic Oceanographic and Meteorological Laboratory/Hurricane Research Division, and Cooperative Institute for \\ Marine and Atmospheric Studies, Rosenstiel School of Marine and Atmospheric Science, University of Miami, Miami, Florida \\ ROBERT F. ROGERS \\ NOAA/Atlantic Oceanographic and Meteorological Laboratory/Hurricane Research Division, Miami, Florida \\ ZHAN ZHANG AND ViJAY TALLAPRAGADA \\ NOAA/NWS/NCEP/Environmental Modeling Center, College Park, Maryland
}

(Manuscript received 2 June 2017, in final form 20 October 2017)

\begin{abstract}
Forecasts from the operational Hurricane Weather Research and Forecasting (HWRF)-based ensemble prediction system for Hurricane Edouard (2014) are analyzed to study the differences in both the tropical cyclone inner-core structure and large-scale environment between rapidly intensifying (RI) and nonintensifying (NI) ensemble members. An analysis of the inner-core structure reveals that as deep convection wraps around from the downshear side of the storm to the upshear-left quadrant for RI members, vortex tilt and asymmetry reduce rapidly, and rapid intensification occurs. For NI members, deep convection stays trapped in the downshear/downshear-right quadrant, and storms do not intensify. The budget calculation of tangential wind tendency reveals that the positive radial eddy vorticity flux for RI members contributes significantly to spinning up the tangential wind in the middle and upper levels and reduces vortex tilt. The negative eddy vorticity flux for NI members spins down the tangential wind in the middle and upper levels and does not help the vortex become vertically aligned. An analysis of the environmental flow shows that the cyclonic component of the storm-relative upper-level environmental flow in the left-of-shear quadrants aids the cyclonic propagation of deep convection and helps establish the configuration that leads to the positive radial vorticity flux for RI members. In contrast, the anticyclonic component of the stormrelative mid- and upper-level environmental flow in the left-of-shear quadrants inhibits the cyclonic propagation of deep convection and suppresses the positive radial eddy vorticity flux for NI members. Environmental moisture in the downshear-right quadrant is also shown to be important for the formation of deep convection for RI members.
\end{abstract}

\section{Introduction}

Idealized simulations of tropical cyclones (TCs) have shown that after an initial period of gestation where the spinup of a modeled vortex takes place, a period of rapid

Corresponding author: Hua Leighton, hua.leighton@noaa.gov intensification is observed that continues for up to $12-36 \mathrm{~h}$ (e.g., Ooyama 1969; Nguyen et al. 2011; Gopalakrishnan et al. 2011, 2013, 2016). During this time, the central pressure drops, and the maximum $10-\mathrm{m}$ wind speed increases rapidly until a quasi-steady state near a potential intensity limit is reached. While rapid intensification frequently occurs in these simulations, most observed TCs 
never undergo rapid intensification (Kaplan and DeMaria 2003). The question of why a storm intensifies rapidly then becomes a question of what prevents a storm from intensifying rapidly. Several environmental factors, such as sea surface temperature (SST), vertical wind shear (VWS), and environmental moisture, have been identified as having paramount importance on the intensification process (e.g., Gray 1968; Merrill 1988; DeMaria and Kaplan 1994a; Kaplan and DeMaria 2003). A number of mechanisms have been proposed to explain the negative influence of shear on the evolution of TCs. Tilting of the vortex (DeMaria 1996), "ventilation" of the warm core in the upper levels (Gray 1968; Frank and Ritchie 2001), midlevel ventilation (Tang and Emanuel 2010), and the reduction of moist entropy by shear-induced persistent downdrafts that flush relatively cool, dry air into a TC's inflow layer (Riemer et al. 2010) have all been shown to impede TCs from reaching their potential intensity.

At the same time, recent findings have shown that tropical depressions and weak storms can grow and rapidly intensify in a sheared environment. For instance, observational studies of Tropical Storm Gabrielle (2001; Molinari et al. 2006; Molinari and Vollaro 2010) revealed that the surface pressure dropped $22 \mathrm{hPa}$ in $3 \mathrm{~h}$ despite $13 \mathrm{~m} \mathrm{~s}^{-1}$ of VWS when an intense convective cell developed in the downshear-left quadrant and moved cyclonically inward to a radius of $17 \mathrm{~km}$, which was inside the radius of maximum wind (RMW). Using airborne Doppler radar observations, Reasor et al. (2009) showed that Hurricane Guillermo (1997) intensified rapidly despite $7-8 \mathrm{~m} \mathrm{~s}^{-1}$ of VWS when several particularly strong convective bursts (CBs) formed and rotated cyclonically around the left-of-shear quadrants of the eyewall. A similar evolution between VWS, the upshear propagation of deep convection, and TC intensification was observed in Hurricane Edouard (2014; Rogers et al. 2016; Zawislak et al. 2016). These studies showed that the low-level equivalent potential temperature was maximized in the downshear-right quadrant as downdraft-cooled air left of shear was replenished through surface fluxes when the air traveled around the storm through the upshear quadrants. These fluxes led to high values of convective available potential energy in the downshear quadrants. As a result, deep convection persisted into the upshear-left quadrant and inside the local RMW, causing the intensification of Edouard.

Many of these studies invoke the efficiency argument to explain the relationship between the location of diabatic heating and TC intensification. In the work of Schubert and Hack (1982), it was demonstrated that diabatic heating, which can be associated with CBs within the RMW, may be an efficient means of spinning up the vortex. This relationship between the radial location of diabatic heating and TC intensification was later confirmed by numerical (Nolan et al. 2007), analytical (Vigh and Schubert 2009), and observational (Rogers et al. 2013) studies. By contrast, Smith and Montgomery (2016) pointed out the limitations of Schubert and Hack's (1982) efficiency argument and proposed that deep convection occurring inside the RMW helps spin up the vortex by drawing angular momentum surfaces within and above the boundary layer closer to the center of circulation. When this inward advection of angular momentum exceeds the rate of loss of angular momentum to the surface via surface friction, spinup occurs.

High-resolution forecast models have also provided insights on the three-dimensional intensification problem in a sheared environment (e.g., Chen and Gopalakrishnan 2015, hereafter CG2015; Nguyen and Molinari 2015). In CG2015, the authors used the operational Hurricane Weather Research and Forecasting (HWRF) system to verify predictions of Hurricane Earl (2010) against available inner-core observations to understand the asymmetric rapid intensification of a TC in a sheared environment. The study revealed that the rapid intensification of Earl, which was associated with the development of an upper-level warm core, occurred after persistent deep convection clustered in the downshear-left quadrant. The thermodynamic budget calculation revealed that warming over Earl's low-level center resulted primarily from the radially inward, storm-relative advection of subsidence-induced warm air in the upshear-left region. Their conceptual model demonstrated that warm advection is maximized when deep convection concentrates in the left-of-shear quadrants where convective-scale subsidence collocates with shear-induced mesoscale subsidence. Smith et al. (2017), using the same model simulation of Hurricane Earl, showed that eddy processes played a significant role in intensifying the storm. These eddy processes were not included in previous theories of symmetric spinup above the boundary layer (Ooyama 1982) and within the boundary layer (Montgomery and Smith 2014).

Intensity forecasting schemes often focus on predicting environmental conditions since, as discussed above, they play a paramount role in determining storm structure and intensity change. However, these conditions are usually represented in an oversimplified manner. For example, the Statistical Hurricane Intensity Prediction Scheme (SHIPS) indices (DeMaria and Kaplan 1994b), which have been widely used to study the impact of environmental conditions on intensity change, are calculated as the average over an area surrounding the storm center. Although studies that use the SHIPS indices have demonstrated success in predicting intensity changes from a statistical point of view (DeMaria and 
Kaplan 1994b; Kaplan and DeMaria 2003; Kaplan et al. 2010, 2015), with the exception of very strong TCs, all systems possess some degree of asymmetry when rapid intensification commences. However, simplified environmental indices that have been used to forecast rapid intensification assume an axisymmetric vortex structure and might not represent the impact of the environment on storms with an asymmetric structure.

Recent idealized numerical studies (Nolan 2011; Onderlinde and Nolan 2014, 2016) have elucidated this point and demonstrated that environmental profiles with the same VWS, but different storm-relative helicity, can have different impacts on storm structure and intensity change when other environmental conditions are kept the same. A storm embedded in environmental flow with positive storm-relative helicity intensifies, with convection rotating cyclonically downstream to the downshear-left and upshear-left quadrants. The same storm embedded in environmental flow with negative storm-relative helicity does not intensify, with convection trapped in the downshear-right quadrant. These differences result primarily from the position of convection and associated latent heat fluxes relative to the wind shear vector. Trajectories with a positive stormrelative helicity had a greater recovery of equivalent potential temperature downwind of convection and latent heat flux near the TC core. Air parcels that experienced larger fluxes were more frequently ingested into the TC core, and convection was more readily advected upshear, resulting in intensification.

Recent studies have begun to use ensemble model simulations to address the impact of environmental moisture on storm structure and intensity in a sheared environment. Munsell et al. (2013) showed in the ensemble study of Tropical Storm Erika (2009) that dry-air intrusions are a key factor that keeps storms from intensifying. Rios-Berrios et al. (2016a,b) showed in the ensemble studies of Hurricanes Katia (2011) and Ophelia (2011) that lowertropospheric moisture in the right-of-shear quadrants and midlevel moisture in the downshear quadrants are critical in predicting different intensity scenarios. Without removing the vortex from the calculation of environmental moisture, however, the conclusion in the aforementioned ensemble studies (i.e., Munsell et al. 2013; Rios-Berrios et al. 2016a,b) could also reflect the structure and intensity of the vortex itself instead of just the environmental impact. Recent studies using idealized simulations (Nolan 2011; Onderlinde and Nolan 2014, 2016; Finocchio et al. 2016) have shown that the same vortex could behave differently even though the 850-200-hPa VWS and environmental moisture were the same.

Although these earlier studies proposed possible pathways for the rapid intensification of TCs in sheared environments, they failed to provide guidance on why some TCs intensified rapidly in sheared environments while others did not. What are the robust differences between rapidly intensifying (RI) and nonintensifying (NI) storms in terms of the distribution of convection that can be easily discerned from satellite and aircraft observations? Additionally, what are the robust differences in terms of environmental conditions between RI and NI storms? In this study, we examine the inner-core and shear-relative environmental structures associated with intensity change using the HWRF ensemble forecasts of Hurricane Edouard to link the impact of these environmental factors with Edouard's asymmetric inner-core structure.

Section 2 provides a short description of the HWRF ensemble forecast system, and section 3 gives an overview of the life cycle of Hurricane Edouard. Section 4 briefly describes the ensemble forecast analysis results for Edouard, while section 5 shows the inner-core structural differences between RI and NI storms. Section 6 presents a budget analysis of tangential wind tendency for an RI member and an NI member to identify the key processes that are responsible for the different intensity changes of the two members. Section 7 shows the differences in environmental factors between RI and NI storms and demonstrates how these differences impact the evolution of storm structure and processes operating in the inner core. A summary and concluding remarks are given in the final section.

\section{HWRF ensemble system}

The HWRF system was jointly developed by NOAA's National Weather Service/National Centers for Environmental Prediction (NWS/NCEP) and the Hurricane Research Division of the Atlantic Oceanographic and Meteorological Laboratory under the auspices of the Hurricane Forecast Improvement Project (Gopalakrishnan et al. 2011, 2012, 2013; Tallapragada et al. 2014). HWRF is a coupled model with a triply nested, cloud-resolving atmospheric model coupled to the Princeton Ocean Model (POM) that has been adapted to TCs (POM-TC; Yablonsky and Ginis 2008). Table 1 summarizes the physics schemes for the atmospheric model used in the 2015 operational version of HWRF, which is the version used in this study. The horizontal resolution of this version has been upgraded to $18 \mathrm{~km}$ for the parent domain and 6 and $2 \mathrm{~km}$ for the two vortex-following nests, compared to the horizontal resolution of 27,9 , and $3 \mathrm{~km}$ in previous versions of HWRF. The vertical levels were increased from 43 to 61 with the model top shifting from 50 to $2 \mathrm{hPa}$ in the 2015 HWRF upgrade. The initial conditions and 126-h boundary conditions of the parent domain are from Global Forecast 
TABLE 1. Physics schemes used in the HWRF system.

\begin{tabular}{ll}
\hline \hline \multicolumn{1}{c}{ Physics } & \multicolumn{1}{c}{ Schemes } \\
\hline Microphysics & Ferrier-Aligo (FA) scheme (Ferrier 2005) \\
Cumulus parameterization & The simplified Arakawa-Schubert (SAS) scheme (Arakawa and Schubert 1974; Grell 1993) \\
Surface layer & Modified GFDL surface layer (Kwon et al. 2010; Powell et al. 2003) \\
PBL & Modified GFS PBL scheme (Hong and Pan 1996; Troen and Mahrt 1986; Zhang et al. 2015, 2017) \\
Land surface model & Noah (Koren et al. 1999; Ek et al. 2003) \\
Radiation & Rapid Radiative Transfer Model for GCMs (RRTMG) longwave and shortwave schemes \\
& (Iacono et al. 2008) \\
\hline
\end{tabular}

System (GFS) forecasts. The vortex initialization is adopted to relocate and adjust the initial vortex toward the current pressure and wind observations (Liu et al. 2006; Tallapragada et al. 2014).

The operational 2015 HWRF ensemble system (Zhang et al. 2014) has the same physics configuration as the 2015 operational HWRF system except that the horizontal and vertical resolutions have been kept at 27, 9 , and $3 \mathrm{~km}$ and 43 levels, respectively. Nevertheless, the horizontal and vertical resolutions of the HWRF ensemble system used in this study are kept the same as the 2015 operational HWRF system (i.e., 18-, 6-, and 2-km horizontal resolution and 61 levels of vertical resolution). Large-scale perturbations are created by using initial conditions and lateral boundary conditions from 20 Global Ensemble Forecast System ${ }^{1}$ (GEFS) members, whose perturbations are orthogonal to each other to provide effective and optimal initial perturbations (Wei et al. 2008). In this study, HWRF ensemble forecasts of Hurricane Edouard are used to provide a large sample of TC forecasts from which we chose two subsets, one group of runs in which TCs undergo rapid intensification and another group of runs in which the TCs do not intensify. The objective is to study how the interaction of the TC vortex and its environment influences inner-core structure and intensity change. Using the ensemble forecast approach, we hope to provide meaningful findings that are more robust compared to a case study where only one simulation is analyzed.

\section{Overview of Hurricane Edouard}

The entire life cycle of Hurricane Edouard, from early genesis to late dissipation, occurred over the open ocean with minimal impact, if any, from land interaction. The TC originated from a tropical wave off the coast of Africa late on 6 September and was designated a tropical depression at 1200 UTC 11 September after deep

\footnotetext{
${ }^{1}$ http://www.emc.ncep.noaa.gov/index.php?branch=GEFS.
}

convection had become sufficiently organized (Stewart 2014). The depression slowly strengthened into a tropical storm on 12 September while moving northwestward and became a hurricane early on 14 September after rapidly intensifying (Rogers et al. 2016; Zawislak et al. 2016). Edouard reached its peak intensity of $105 \mathrm{kt}$ $\left(1 \mathrm{kt}=0.51 \mathrm{~m} \mathrm{~s}^{-1}\right)$ at 1200 UTC 16 September then weakened to a tropical storm late on 18 September after it moved eastward and encountered strong westerly VWS. Edouard degenerated into a strong posttropical cyclone early on 19 September about $400 \mathrm{n}$ mi $(1 \mathrm{n} \mathrm{mi}=$ $1.852 \mathrm{~km}$ ) west of the western Azores Islands.

\section{Description of ensemble forecast results from Hurricane Edouard}

Two sets of retrospective HWRF ensemble forecasts of Hurricane Edouard, driven by 20 GEFS members initialized at 1200 UTC (henceforth Ens1200) and 1800 UTC11 September (henceforth Ens1800), were performed. For Ens1200, 18 members followed a northwestward movement during the 126-h period, while two members moved westward at the end stage of the forecast period (Fig. 1a). Most of the tracks for Ens1200 were to the southwest of the best track from the National Hurricane Center. The spread of tracks for Ens1800 (Fig. 1d) was larger than that of Ens1200, especially after $24 \mathrm{~h}$, but the overall movement followed the best track. The forecasted intensities for both Ens1200 (Figs. 1b,c) and Ens1800 (Figs. 1e,f) showed a large spread ranging from NI to RI members. Although the majority of the ensemble members forecasted Hurricane Edouard to be weaker than the best track, the wide range between the NI and RI samples and well-behaved spread in the tracks made this case ideal for using an ensemble approach to understand the rapid intensification problem.

To study the differences in TC structure between RI and NI storms, six members with the strongest intensification rate and six members with the weakest intensification rate, based on a 24-h pressure drop, were selected from the combined $40 \mathrm{HWRF}$ ensemble forecast members of these two sets of HWRF ensemble forecasts. 

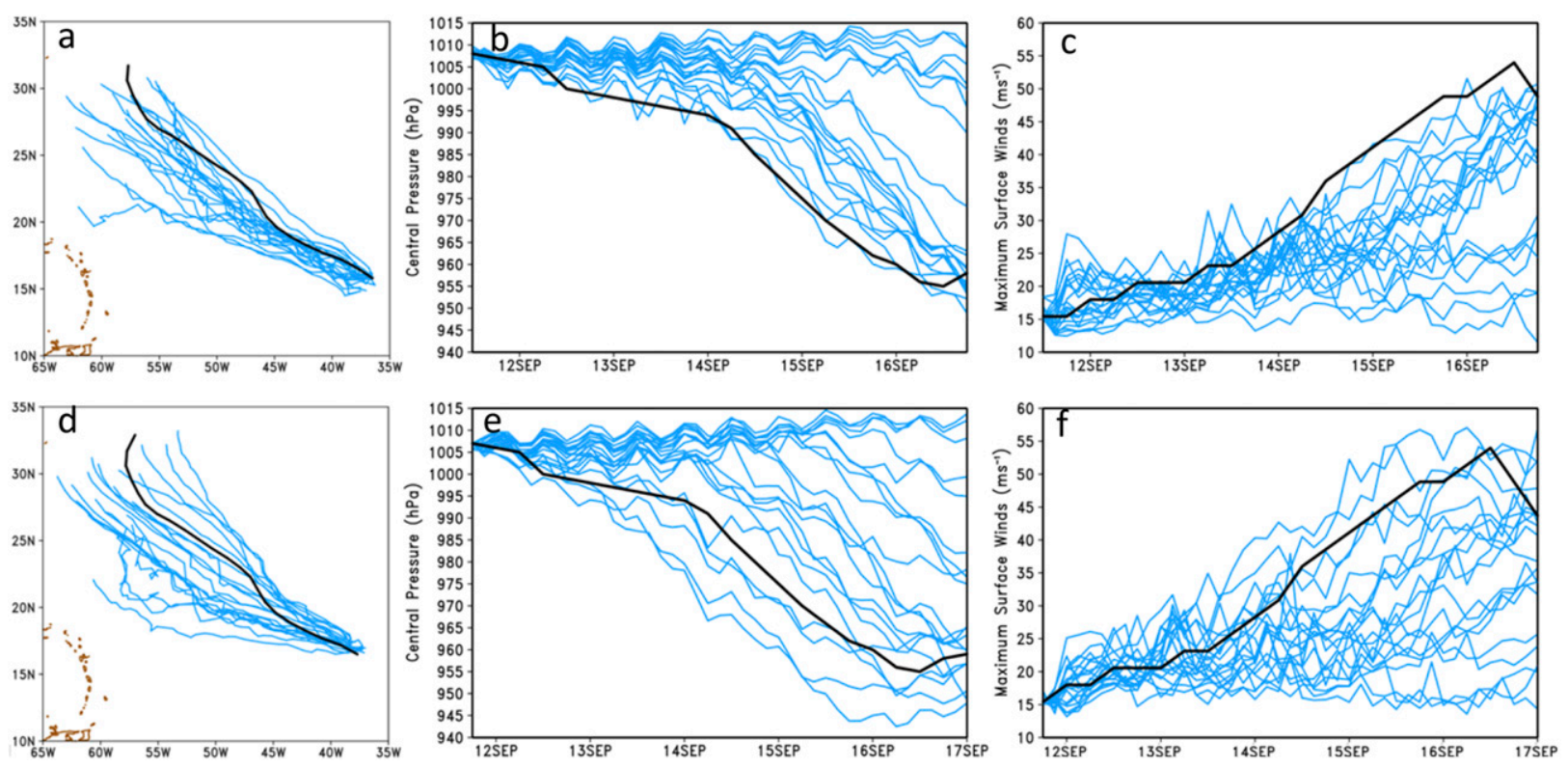

FIG. 1. (a) Tracks and time series, (b) central pressure, and (c) maximum winds with an initial time of 1200 UTC 11 Sep 2014. (d)-(f) As in (a)-(c), respectively, but with an initial time of 1800 UTC 11 Sep 2014. Thin blue lines represent the ensemble forecast, and thick black lines indicate the best track.

The RI members were aligned such that rapid intensification onset coincided with each other. The time window from $36 \mathrm{~h}$ prior to rapid intensification onset to $36 \mathrm{~h}$ after rapid intensification onset was chosen to study the structural changes associated with pre-rapid intensification, rapid intensification onset, and late-rapid intensification stages. Rapid intensification onset was marked as $0 \mathrm{~h}$. For the six NI members, a 72-h time window between 0000 UTC 13 and 0000 UTC 16 September was selected, with 1200 UTC 14 September marked as $0 \mathrm{~h}$. The mean track for the NI members had a larger southern bias compared to that of NI members (not shown).

To understand the behavior of RI versus NI members, the evolution of intensity and $\mathrm{RMW}^{2}$ for members in both groups is shown in Fig. 2. Thin lines represent individual members, and thick lines represent the mean of each group. Blue lines are for the NI group, and red lines are for the RI group. As shown in Fig. 2a, the central pressure of the RI and NI composites is similar before $0 \mathrm{~h}$, with no clear trend other than the semidiurnal oscillation. CG2015 also noticed the semidiurnal oscillation in the pressure field before the rapid intensification onset of Hurricane Earl in the HWRF forecast. After $0 \mathrm{~h}$, the semidiurnal oscillation becomes less pronounced in the RI composite pressure, mainly because the small

\footnotetext{
${ }^{2}$ RMW is calculated based on the azimuthal mean of the wind speed at 2-km altitude.
}

amplitude of oscillation is superposed on a large and rapid pressure change. The maximum wind speeds of the RI and NI composites, which are calculated from the azimuthal mean of the wind speed at $2-\mathrm{km}$ altitude, are very close to each other between -36 and $-2 \mathrm{~h}$ but diverge rapidly after $-2 \mathrm{~h}$ (Fig. $2 \mathrm{~b}$ ). The RI composite wind speed increases with time, and the NI composite wind speed decreases with time, eventually leveling off between 15 and $20 \mathrm{~m} \mathrm{~s}^{-1}$. The RMW (Fig. 2c) of the NI composite fluctuates significantly throughout the 72-h period. In contrast, the RMW of the RI composite fluctuates much less after rapid intensification onset. This RMW behavior occurs because the RMW is not well defined when storm structure is not well organized. In that case, the RMW can be greatly influenced by the location of deep convection, which can lead to the RMW shifting inward when a new center forms near the deep convection (Molinari et al. 2006; Nguyen and Molinari 2015).

Although the composite pressure, maximum winds, and RMW correlate well with one another throughout the 72-h period of interest, there are a few interesting features worthy of note. First, the composite pressure for both the RI and NI members shows very little change between -36 and $0 \mathrm{~h}$, but the composite maximum wind speed increases slightly. Second, the maximum winds for the RI members increase slowly in the early rapid intensification stage $(0-18 \mathrm{~h})$ and rapidly in the later rapid intensification stage (18-36h) for the RI composite, yet 


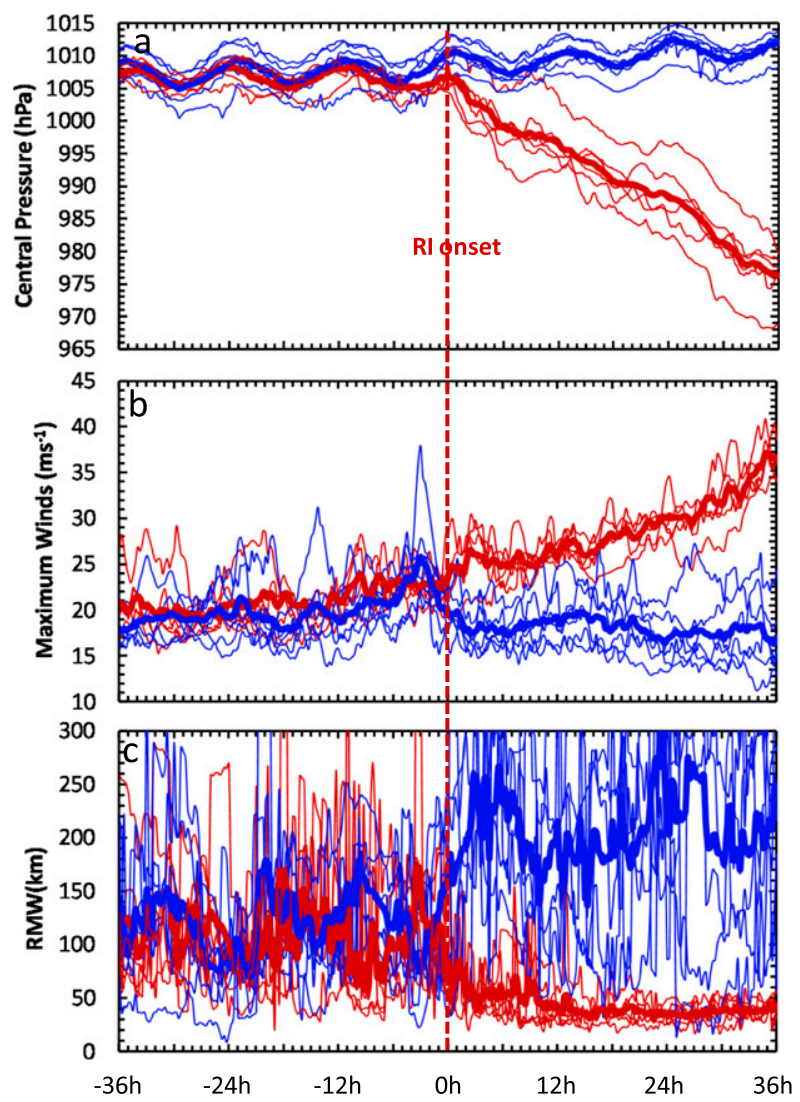

FIG. 2. Time series of (a) central pressure, (b) maximum winds, and (c) the RMW for six RI (red line) and six NI (blue line) members. Thick lines represent the mean value of each group, and thin lines represent individual members.

the pressure decreases at a relatively uniform rate. Third, the slow increase of wind speed in the early rapid intensification stage is associated with the rapid contraction of RMWs, and the rapid increase in the later rapid intensification stage is associated with steady RMWs, which has also been observed in other studies (Chen et al. 2011; Qin et al. 2016).

SHIPS predictors for the RI and NI members are examined (Fig. 3) to determine if this simplified environmental index can account for the drastic intensity differences between the RI and NI groups. Figure 3a shows the time series of VWS magnitude calculated as the wind difference between 850 and $200 \mathrm{hPa}$ within a $500-\mathrm{km}$ radius. Similar to Fig. 2, the thin lines represent the individual members, and thick lines represent the composite mean for each group. The difference in shear magnitude between the two groups is small $\left(\sim 1.5 \mathrm{~m} \mathrm{~s}^{-1}\right.$ on average) in the first $12 \mathrm{~h}$ (between -36 and $-24 \mathrm{~h}$ ), and the mean shear for both groups is about $9 \mathrm{~m} \mathrm{~s}^{-1}$. The VWS for the RI composite decreases after $-24 \mathrm{~h}$, while the VWS for the NI composite increases to $12 \mathrm{~m} \mathrm{~s}^{-1}$

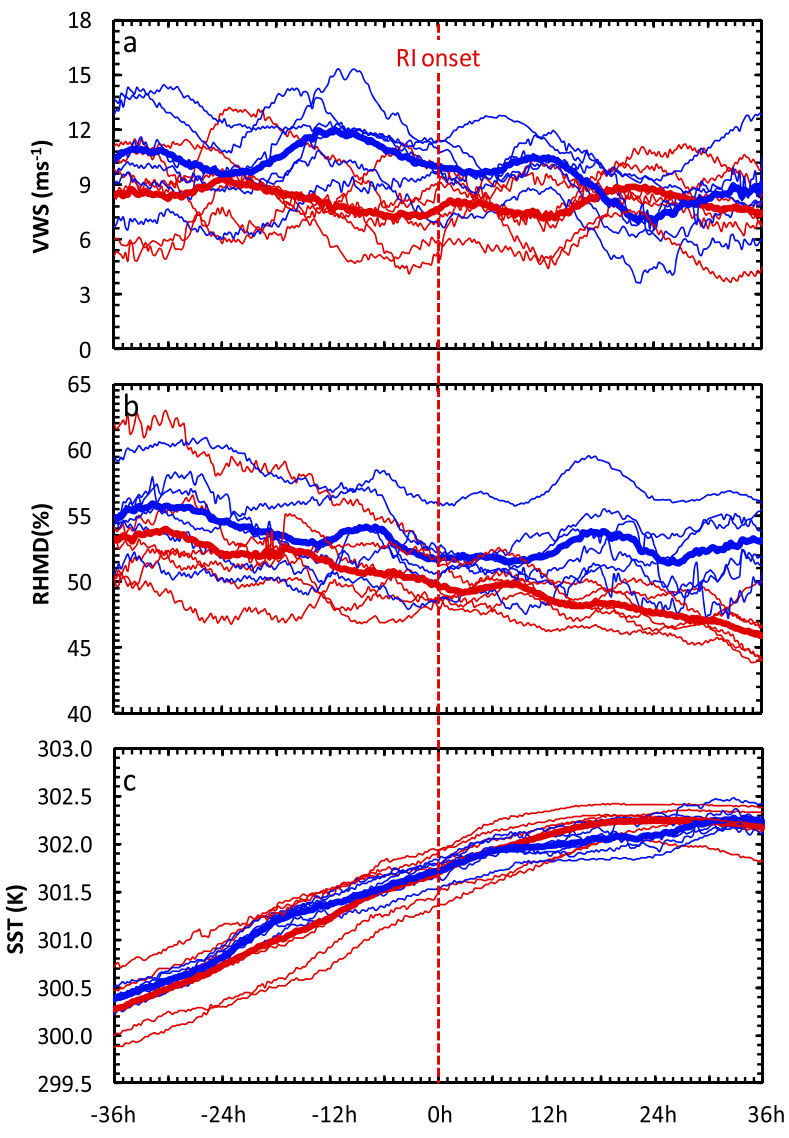

FIG. 3. Time series of (a) environment shear, (b) midlevel relative humidity, and (c) SSTs for six RI (red line) and six NI (blue line) members. Thick lines represent the mean value of each group, and thin lines represent individual members.

at $-12 \mathrm{~h}$ and then decreases with time. The difference in VWS between the two groups is about $2 \mathrm{~m} \mathrm{~s}^{-1}$ at $0 \mathrm{~h}$ with about $10 \mathrm{~m} \mathrm{~s}^{-1}$ shear for the NI composite and $8 \mathrm{~m} \mathrm{~s}^{-1}$ for the RI composite. Kaplan and DeMaria (2003) suggested $5 \mathrm{~m} \mathrm{~s}^{-1}$ as the threshold value of VWS, above which the probability of intensification decreases significantly. Zehr (1992) observed that TCs did not develop when the shear exceeded $15 \mathrm{~m} \mathrm{~s}^{-1}$. With both 8 and $10 \mathrm{~m} \mathrm{~s}^{-1}$ of VWS falling within the range of $5-15 \mathrm{~m} \mathrm{~s}^{-1}$, it is unlikely that the $2 \mathrm{~m} \mathrm{~s}^{-1}$ difference in VWS could cause such a drastic difference in intensity change, especially when the intensity of the two groups is similar.

Figure $3 \mathrm{~b}$ shows the environmental midlevel relative humidity calculated between 700 and $500 \mathrm{hPa}$ within a 200-800-km ring, following the SHIPS index calculation, which reveals that the environment is drier for the RI group, especially so during $12-36 \mathrm{~h}$. The relative humidity in the lower level $(850-700 \mathrm{hPa})$ bears an overall trend that is similar to the midlevel humidity (not shown). This seems contradictory to the well-accepted idea that a moist environment is 

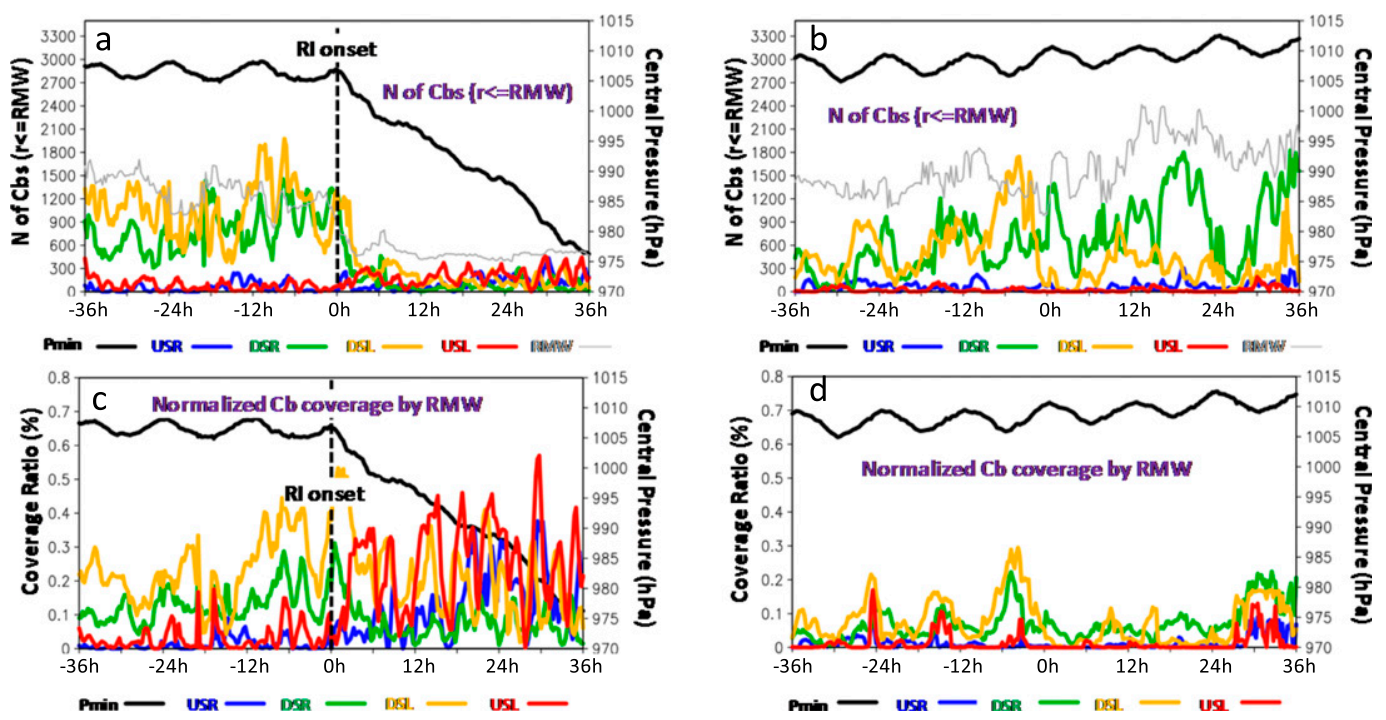

FIG. 4. (top) Time series of the composite CB count within the RMW (blue line: upshear right; green line: downshear right; yellow line: downshear left; and red line: upshear left) superposed with the composite central pressure (black line) and RMW (gray line) for (a) RI and (b) NI members. The RMW is multiplied by 100 and adopts the scale on the left axis. (bottom) The time series of the CB coverage ratio (blue line: upshear right; green line: downshear right; yellow line: downshear left; and red line: upshear left) is superposed with the composite central pressure (black line) and RMW (gray line) for (c) RI and (d) NI members.

favorable for genesis and rapid intensification as shown in earlier studies (Kaplan and DeMaria 2003; Nolan and McGauley 2012; Tao and Zhang 2014). However, other studies have pointed out that too moist of an environment might not favor storm intensification because of the formation of outer rainbands. Barnes et al. (1983) hypothesized that outer rainbands could act as a barrier to the boundary layer inflow that feeds the eyewall. Wang (2009) showed that heating associated with outer spiral rainbands can reduce the horizontal pressure gradient across the RMW and thus reduce storm intensity in terms of maximum wind in the lower troposphere. Despite the potentially negative impacts of a moist environment on TC intensification, the relative humidity differences shown here (i.e., $5 \%$ or less) are relatively small.

The mean SST (Fig. 3c) for the two groups is similar, which suggests the role of SST in contributing to the drastic intensity difference between the two groups is minimal when compared to other environmental factors. Although there are systematic differences in the VWS and environmental relative humidity between the RI and NI groups, it is hard to attribute the drastic intensity differences between the two groups to a $2 \mathrm{~m} \mathrm{~s}^{-1}$ difference in VWS and a less than $5 \%$ difference in relative humidity in the environment. We next examine the inner-core structure to determine if there are robust differences between the RI and NI groups.

\section{Evolution of the inner-core structure}

\section{a. Azimuthal distribution of deep convection}

Figure 3a shows that both the RI and NI groups are embedded in a sheared environment of $8-10 \mathrm{~m} \mathrm{~s}^{-1}$ of 850 200-hPa VWS. Previous studies (Frank and Ritchie 1999; Reasor et al. 2004, 2013) have pointed out that VWS can significantly impact the azimuthal distribution of convection, which can influence storm intensity through asymmetric spinup mechanisms (CG2015). The radial location of deep convection relative to the RMW also plays a critical role in storm intensification through efficiency arguments (Schubert and Hack 1982) and the inward advection of the angular momentum surface in the planetary boundary layer (PBL) due to the inflow induced by deep convection (Smith and Montgomery 2016).

To examine the distribution of convection in the two groups, the composite of the shear-oriented CB count within the RMW is plotted in Figs. 4a and 4b. The composite mean of the central pressure and RMW are also superposed. A grid point is flagged as a CB if the 20-dBZ contour of reflectivity reaches $14-\mathrm{km}$ altitude and surface reflectivity is greater than $20 \mathrm{dBZ}$, following Tao and Jiang (2015). For the RI composite (Fig. 4a), CBs within the RMW concentrate in the downshear quadrants (yellow and green lines) between -36 and $0 \mathrm{~h}$. At rapid intensification onset, the $\mathrm{CB}$ count inside the RMW decreases as the RMW contracts. For the NI composite, 

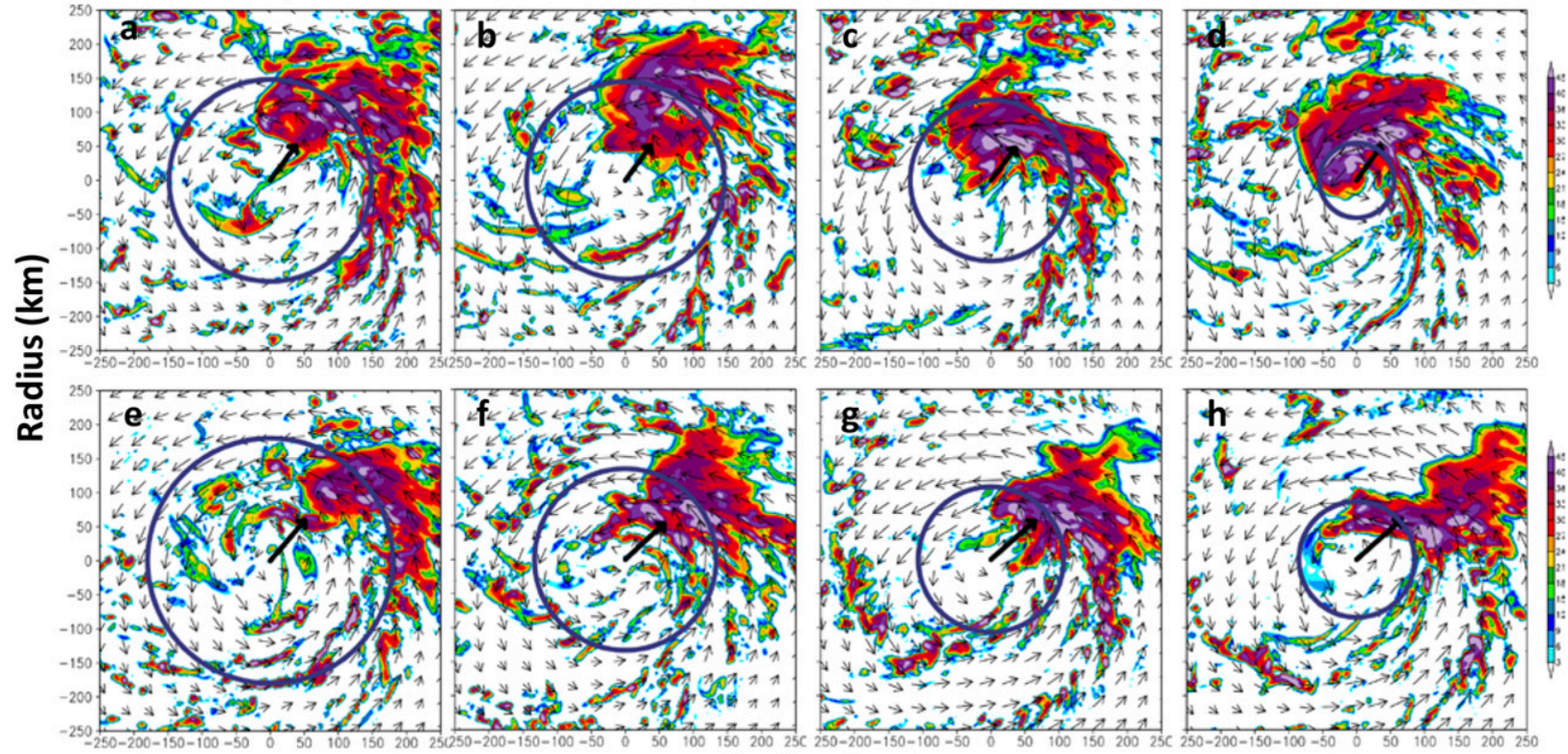

\section{Radius (km)}

FIG. 5. The evolution of radar reflectivity superposed with storm-relative flow vectors at $1-\mathrm{km}$ altitude every $3 \mathrm{~h}$ for one selected (a)-(d) RI and (e)-(h) NI member. Rapid intensification onset occurs in (c). Blue circles indicate the azimuthal-mean RMW at 2-km altitude, and thick black arrows describe the shear vector.

CBs within the RMW also concentrate in the downshear quadrants between -36 and $0 \mathrm{~h}$, but the $\mathrm{CB}$ count is smaller than that of the RI composite. Between 0 and $36 \mathrm{~h}$, the total number of CBs for the NI composite is comparable to that from -36 to $0 \mathrm{~h}$, but the majority of CBs remain concentrated in the downshear-right quadrant. The composite-mean pressure rises slightly during this period. Although Figs. $4 \mathrm{a}$ and $4 \mathrm{~b}$ show a distinct distribution of CBs, especially after $0 \mathrm{~h}$, the small number of CB counts inside the RMW in the RI composite due to the RMW contraction makes it difficult to discern meaningful information about the azimuthal distribution of CBs after rapid intensification onset.

To take into account the change in RMW, the percentage of $\mathrm{CB}$ coverage in each quadrant within the RMW is plotted in Figs. 4c and 4d. The RI composite (Fig. 4c) shows that CB coverage in the downshear-left quadrant slightly outweighs that in the downshear-right quadrant between -36 and $0 \mathrm{~h}$ (rapid intensification onset). This pattern continues until a few hours after rapid intensification onset, when $\mathrm{CB}$ coverage in the upshear-left quadrant increases quickly and becomes comparable to that in the downshear-left quadrant. At the same time, $\mathrm{CB}$ coverage in the downshear-right quadrant decreases rapidly. This marks the transition of downshear convection in the pre-rapid intensification period to left-of-shear convection in the RI period, which is consistent with previous observations (e.g.,
Reasor et al. 2009; Rogers et al. 2016), including observations of Edouard's evolution [see Figs. 4-6 of Rogers et al. (2016)]. Around 18h, CB coverage in the upshear-right quadrant increases significantly, suggesting deep convection wraps around into the upshear-right quadrant, and the storm becomes more symmetric. In contrast to the evolution of $\mathrm{CB}$ coverage in the RI composite, the $\mathrm{CB}$ coverage in the NI composite concentrates in the downshear quadrants for the entire 72-h period, and the percentage of CB coverage is much smaller because of the larger RMW. The striking difference between the RI and NI composites of CBs, and between the pre-rapid intensification and rapid intensification stages for the RI composite, suggests that deep convection making its way into the upshear-left quadrant is closely tied to intensity change.

Figure 5 shows the evolution of convection at 3 -h intervals by plotting radar reflectivity snapshots for one RI member (Figs. 5a-d) and one NI member (Figs. 5e-h). The first snapshot for the RI and NI members is at -6 and $-10 \mathrm{~h}$, respectively, so that both members have a similar horizontal distribution of convection with respect to radial location and shear-oriented azimuthal location. As seen in Fig. 5a (RI member) and Fig. 5e (NI member), high radar reflectivity ( $\geq 40 \mathrm{dBZ}$ ) is concentrated in the downshear-right quadrant with part of it inside the RMW for both the RI and NI members. The RMW of the NI member is about $30 \mathrm{~km}$ larger than that 

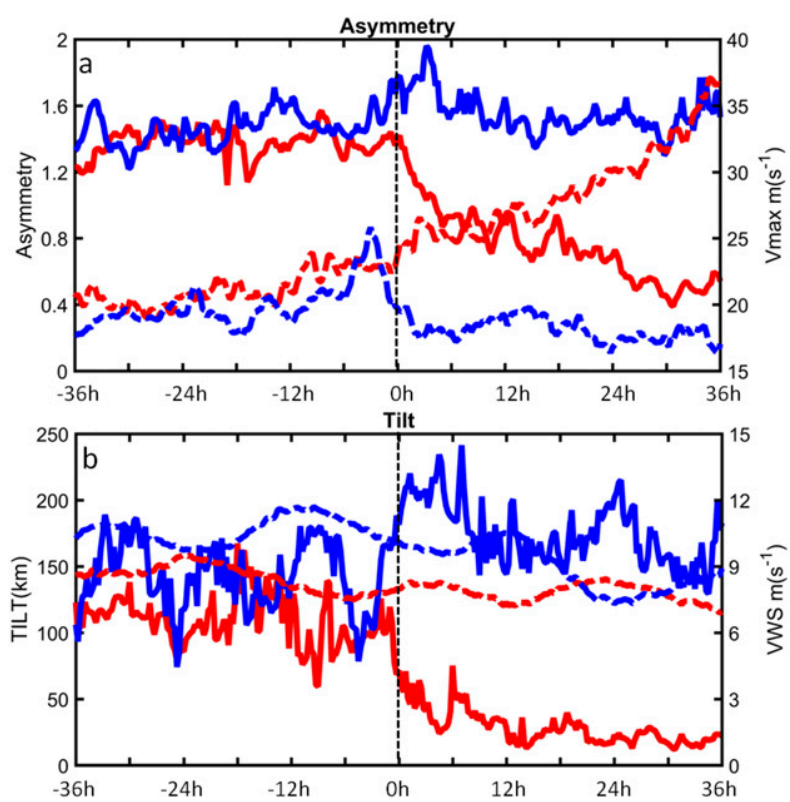

FIG. 6. Time series of (a) composite maximum wind (dashed line) and composite vortex asymmetry (solid line) for RI (red line) and NI (blue line) members and (b) composite VWS (dashed line) and composite vortex tilt (solid line) between 2- and 8-km altitudes for RI (red line) and NI (blue line) members.

of the RI member. Three hours later, the high radar reflectivity rotates cyclonically to cover some of the downshear-left quadrant in both members, and the RMW of the NI member is slightly smaller than that of the RI member. In another $3 \mathrm{~h}$, which corresponds to rapid intensification onset for the RI member, the high radar reflectivity rotates to cover most of the downshear-left quadrant, with a significant portion inside the RMW. In contrast, much of the high radar reflectivity for the NI member remains in the downshear-right quadrant with a smaller portion inside the RMW. Then, $3 \mathrm{~h}$ later, the high radar reflectivity of the RI member wraps around into the upshear-left quadrant, along with a sizable portion of high reflectivity inside the contracting RMW, while high radar reflectivity for the NI member appears to be sheared off and remains in the downshear-right quadrant.

\section{b. Asymmetry and vortex tilt}

Figures 4 and 5 suggest that the vortex becomes less asymmetric as it intensifies. We next quantify asymmetry for both the RI and NI groups. Figure 6a shows the time evolution of the composites of inner-core asymmetry (defined as $R \leq 1.5 \mathrm{RMW}$ ) and the maximum wind speed for the RI and NI groups. Asymmetry is calculated as the ratio of wavenumber- 1 plus wavenumber- 2 amplitude over the wavenumber- 0 amplitude for the radar reflectivity at $2-\mathrm{km}$ altitude. Overall, asymmetry change is inversely proportional to intensity change in both groups. For the NI group, asymmetry remains around 1.5 with some fluctuations. For example, the maximum wind speed increases between -12 and $-3 \mathrm{~h}$ and between 6 and $15 \mathrm{~h}$ when asymmetry decreases. Maximum wind speed decreases between -3 and $3 \mathrm{~h}$ and between 15 and $24 \mathrm{~h}$ when asymmetry increases. For the RI group, asymmetry is close to that of the NI group between -36 and $0 \mathrm{~h}$. However, it quickly drops from 1.3 at $0 \mathrm{~h}$ (rapid intensification onset) to 0.8 at $5 \mathrm{~h}$. The asymmetry fluctuates while decreasing slowly between 5 and $18 \mathrm{~h}$ then reduces continuously until $30 \mathrm{~h}$, reaching 0.4 before leveling off. The decreasing asymmetry between 0 and $30 \mathrm{~h}$ in the RI group is a manifestation of deep convection wrapping around into the upshear quadrants and represents an axisymmetrization process. Although there is generally an inverse relationship between asymmetry change and intensity change, the most rapid wind speed increase for the RI group between 30 and $36 \mathrm{~h}$ is not related to the asymmetry decrease, which might suggest that once asymmetry reaches a certain threshold value, intensification might not require further axisymmetrization.

From a potential vorticity (PV) perspective, asymmetry and tilt are closely tied to each other. Idealized numerical experiments (Jones 1995) that study vortex tilt usually impose VWS on a vertically upright and horizontally symmetric vortex. In this scenario, VWS will tilt the vortex, but tilt magnitude will be much smaller than implied by advective processes because of the resilience of the vortex (Jones 1995). The PV anomaly associated with the displaced upper-level circulation center will induce an ascent at lower levels because of PV penetration (Hoskins et al. 1985) and, therefore, disrupt the initially symmetric vortex. However, most vertically upright storms in the real world develop from horizontally asymmetric and shallow vortices. Deep convection can help advect the low-level vorticity to the upper level and advance the shallow vortex to a deep yet tilted vortex. Therefore, deep convection evolution is closely tied to tilt precession.

Figure $6 \mathrm{~b}$ shows the time series of the composite vortex tilt (solid line) and VWS magnitude (dashed line) for the RI (red line) and NI (blue line) groups. Tilt is defined as the horizontal displacement between the upper-level circulation center $(z=8 \mathrm{~km})$ and the lowerlevel circulation center $(z=2 \mathrm{~km})$. The tilt magnitude for the RI group is about $100 \mathrm{~km}$ between -36 and $0 \mathrm{~h}$ and declines rapidly at $0 \mathrm{~h}$ (rapid intensification onset). The mean tilt during $12-36 \mathrm{~h}$ is about $20 \mathrm{~km}$, which is about 10-20 km inside the RMW (Fig. 3c). The tilt for the NI group fluctuates around $130 \mathrm{~km}$, with a $100-\mathrm{km}$ amplitude between -36 and $0 \mathrm{~h}$. It increases to $200 \mathrm{~km}$ at 
around $2 \mathrm{~h}$ and fluctuates around $160 \mathrm{~km}$ during $2-36 \mathrm{~h}$ when intensity is slowly weakening (Figs. $4 \mathrm{~b}$ and $4 \mathrm{~d}$ ). A closer examination of the upper-level flow field reveals that there is no closed circulation in the upper level during $0-36 \mathrm{~h}$ for the NI group. Therefore, the large tilt represents the top of the previously tilted vortex that has been blown off. Figure $6 \mathrm{~b}$ shows there is no clear relationship between VWS and tilt magnitude. The VWS remains at around $8-10 \mathrm{~m} \mathrm{~s}^{-1}$ for the RI and NI groups, respectively, with small fluctuations for both groups. However, tilt magnitude, especially for the RI group, decreases drastically at around $0 \mathrm{~h}$ (rapid intensification onset) even though the VWS increases slightly.

Comparing Figs. 6a and 6b, we find that the evolution of asymmetry and tilt are similar during the 72-h window of interest for the NI group. However, the evolution of asymmetry and tilt for the RI group behaves differently from the NI group, with the tilt leveling off while the asymmetry continues decreasing until $30 \mathrm{~h}$. Comparing Fig. 6 b with Fig. 2c, we find that tilt evolution is similar to the RMW evolution in both groups. The difference between the RMW and the tilt (not shown) indicates that the vortex tilt is smaller than the RMW for most of the time in the RI composite. For the NI composite, the tilt is smaller than the RMW only between -18 and $0 \mathrm{~h}$.

Previous studies have shown that tilt direction relative to shear direction is crucial for rapid intensification. Zhang and Tao (2013) showed that rapid intensification occurred when the tilt was $90^{\circ}$ to the left of the shear vector. Before we show the relationship between tilt direction and shear direction, we first show both directions separately. As seen in Fig. 7a, the shear vectors for the RI and NI groups are southwesterly, with the shear vector for the NI group having a slightly more westerly component. The time series of the tilt direction (Fig. 7b) shows a similar trend to the shear direction (Fig. 7a) in both groups between -36 and $0 \mathrm{~h}$ but with more fluctuations. The tilt direction of the $\mathrm{RI}$ group rotates cyclonically at $-3 \mathrm{~h}$, which is associated with deep convection propagating downstream (cf. Figs. 4 and 5). The tilt direction of the RI group fluctuates significantly after $5 \mathrm{~h}$ with an amplitude greater than $90^{\circ}$, corresponding to the episodic deep convection that originates in the downshear-left quadrant and works its way downstream while dissipating. This suggests that tilt behavior is more complicated than monotonic cyclonic precession. In contrast to the tilt direction of the RI group, the tilt direction for the NI group changes little.

To view the relationship between the shear and tilt directions, Fig. 7c shows a time series of the difference between the shear and tilt directions. Positive values indicate tilt direction is to the left of the shear direction and vice versa. As can be seen, the difference between the shear and the tilt directions is small for both the RI and NI groups
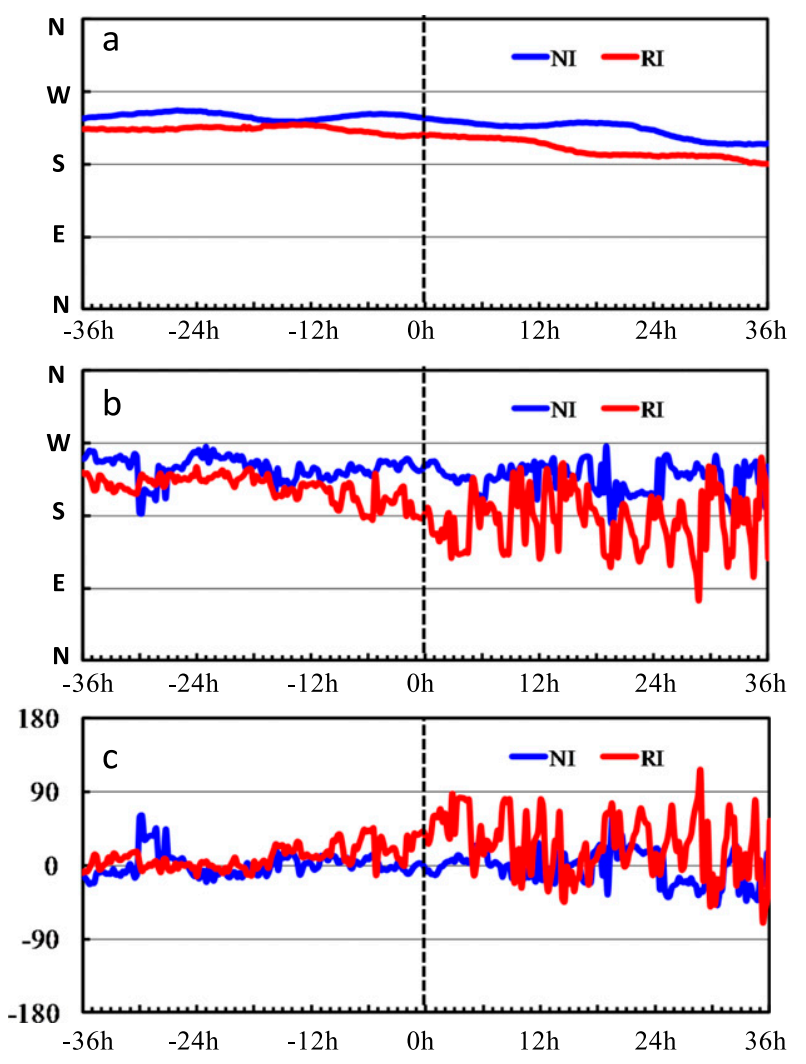

FIG. 7. Time series of (a) composite VWS direction for RI (red line) and NI (blue line) members, (b) composite tilt direction for RI (red line) and NI (blue line) members, and (c) the directional difference between the shear and tilt directions. Positive values indicate tilt direction is to the left of the shear direction and vice versa.

between -36 and $-12 \mathrm{~h}$, which indicates a downshear tilt during this period. This is consistent with deep convection remaining concentrated in the downshear quadrants, as shown in Fig. 4. After $-12 \mathrm{~h}$, the tilt vector rotates cyclonically to the left of the shear vector in the RI group, but the difference between the shear and tilt directions is smaller than $45^{\circ}$. This means that even though the tilt is downshear left, it is more downshear than left of shear. The downshear-left tilt at this time is also consistent with Fig. 4c, which shows that deep convection is more concentrated downshear left inside the RMW. The downshear/ downshear-left tilt remains for a few hours and then rotates cyclonically farther toward the left of shear, as the difference between the shear and tilt vectors exceeds $45^{\circ}$.

At around $5 \mathrm{~h}$, the difference between the shear and tilt directions fluctuates significantly, which is caused by the fluctuation of the tilt direction (Fig. 7b) and implies episodic cyclonic tilt precession. Nevertheless, the mean tilt direction relative to the shear direction does show a "downshear left" tilt equilibrium. This behavior was also shown by Reasor et al. (2004) in a numerical study without diabatic heating. They attributed the downshear-left tilt 
equilibrium to a vortex Rossby wave damping mechanism and argued that the diabatically driven secondary circulation contributed indirectly to vortex resiliency against shear by increasing the Rossby radius of deformation and enhancing the radial gradient of azimuthal-mean potential vorticity. Compared to the results of Zhang and Tao (2013), which showed that rapid intensification occurred when tilt was $90^{\circ}$ to the left of the shear vector, Fig. $7 \mathrm{c}$ shows that the vortex rarely achieves a tilt that is $90^{\circ}$ left of the shear vector, and downshear-left tilt is necessary for rapid intensification onset.

\section{Tangential momentum budget}

Previous studies have suggested that flow asymmetries generally play a negative role in storm intensification (e.g., Yang et al. 2007; Bryan et al. 2010), yet all hurricanes evolve from asymmetries. Recently, a few studies (e.g., Persing et al. 2013; Smith et al. 2017) have shown that combined eddy processes associated with vortical plume structures can enhance the overturning circulation and contribute to an intensifying storm. While these structures are important for TC intensification, not all disturbances with deep convection develop into hurricanes. This highlights the importance of better understanding why some eddy processes help intensify the vortex while others do not. To address this problem, we performed a budget analysis of the tangential wind tendency following

$$
\begin{aligned}
\frac{\partial\langle v\rangle}{\partial t}= & -\langle u\rangle\langle f+\zeta\rangle-\langle w\rangle \frac{\partial\langle v\rangle}{\partial z}-\left\langle u^{\prime} \zeta^{\prime}\right\rangle-\left\langle w^{\prime} \frac{\partial v^{\prime}}{\partial z}\right\rangle \\
& +\left\langle\frac{1}{\rho r} \frac{\partial p^{\prime}}{\partial \lambda}\right\rangle+\left\langle D_{\mathrm{dh}}\right\rangle+\left\langle D_{\mathrm{dv}}\right\rangle,
\end{aligned}
$$

which is the same equation as Eq. (4) in Smith et al. (2017). Here, the azimuthal average is denoted by angle brackets, and the departure from the azimuthal mean (or eddy) is denoted by the prime. The storm-relative radial, tangential, and vertical components of velocity in cylindrical coordinates are given by $u, v$, and $w$, respectively. The vertical component of relative vorticity is given by $\zeta$, and $f$ is the Coriolis parameter. The terms on the right-hand side of Eq. (1) are, respectively, the mean radial influx of absolute vertical vorticity, the mean vertical advection of mean tangential momentum, the eddy radial vorticity flux, the vertical advection of eddy tangential momentum, the azimuthal perturbation pressure gradient force per unit mass, and the horizontal and vertical diffusive tendencies.

Figure 8 shows the azimuthal mean of the three velocity components for the RI member and all the terms in Eq. (1) averaged between -3 and $0 \mathrm{~h}$ (cf. Figs. 5b and $5 c)$ except $(1 / \rho r)\left(\partial p^{\prime} / \partial \lambda\right)$ since this term is very small.
The azimuthal mean of the secondary circulation shows a deep layer of inflow reaching up to $4 \mathrm{~km}$, a broad ring of upward motion between $30-$ and $150-\mathrm{km}$ radius, and outflow between $10-$ and $15-\mathrm{km}$ altitudes. The broad upward motion is the result of time and the azimuthal average when deep convection spirals inward rapidly during the 3-h time window. The primary circulation shows the RMW near the surface is at roughly $120-\mathrm{km}$ radius, and cyclonic tangential winds extend up to $10 \mathrm{~km}$.

Before discussing the contributions of the individual terms in Eq. (1) to the azimuthal-mean tangential wind tendency, the summation (Fig. $8 \mathrm{~g}$ ) of the terms on the right-hand side of Eq. (1) is compared to the local tendency of azimuthal-mean tangential wind from the model output (Fig. 8h). The summation agrees well with the model output in general, yet there are a couple of discrepancies. First, the magnitude of the summation is slightly larger than the local tendency from the model output. Second, the summation overestimates the tendency significantly below $4 \mathrm{~km}$, especially in the PBL. Similar discrepancies are found in Persing et al. (2013; Fig. 10) and Smith et al. (2017; Figs. 11 and 13).

Figure $8 \mathrm{~b}$ shows that the import of mean absolute vorticity has a significant positive contribution to the spinning up of tangential winds in the PBL, yet Fig. 8h suggests this positive contribution by influx of mean vorticity is mostly opposed by other processes that are not captured by the budget analysis, as also shown in Persing et al. (2013) and Smith et al. (2017). The surface friction (Fig. 8f) apparently opposes the spinup in the PBL, but it is not large enough to offset most of the contribution by the influx of mean vorticity. Montgomery and Smith (2014) pointed out that PBL spinup can occur if air parcels converging in the PBL layer reach small radii without losing too much absolute angular momentum. Figure $8 \mathrm{c}$ shows that the vertical advection of the mean tangential wind plays a positive role in spinning up the tangential wind between 8 and $10 \mathrm{~km}$ outside the $50-\mathrm{km}$ radius, yet Fig. 8e shows this positive contribution is mostly offset by the vertical advection of eddy tangential winds in this layer. Figure $8 d$ shows that the radial eddy vorticity flux above $4 \mathrm{~km}$ contributes significantly to the spinup of tangential wind in the middle to upper levels inside the RMW, consistent with the result of Smith et al. (2017).

Figure 9 shows the same fields as in Fig. 8, but for the NI member averaged between -7 and -4 h (cf. Figs. $5 f$ and $5 \mathrm{~g}$ ). There are a few differences between the RI member and NI member in the three velocity components. First, the RMW of the tangential winds near the surface is $100 \mathrm{~km}$, about $20 \mathrm{~km}$ smaller than that of the RI member, yet the cyclonic tangential winds only reach $9 \mathrm{~km}$, about $2 \mathrm{~km}$ shallower than that of the RI member. 


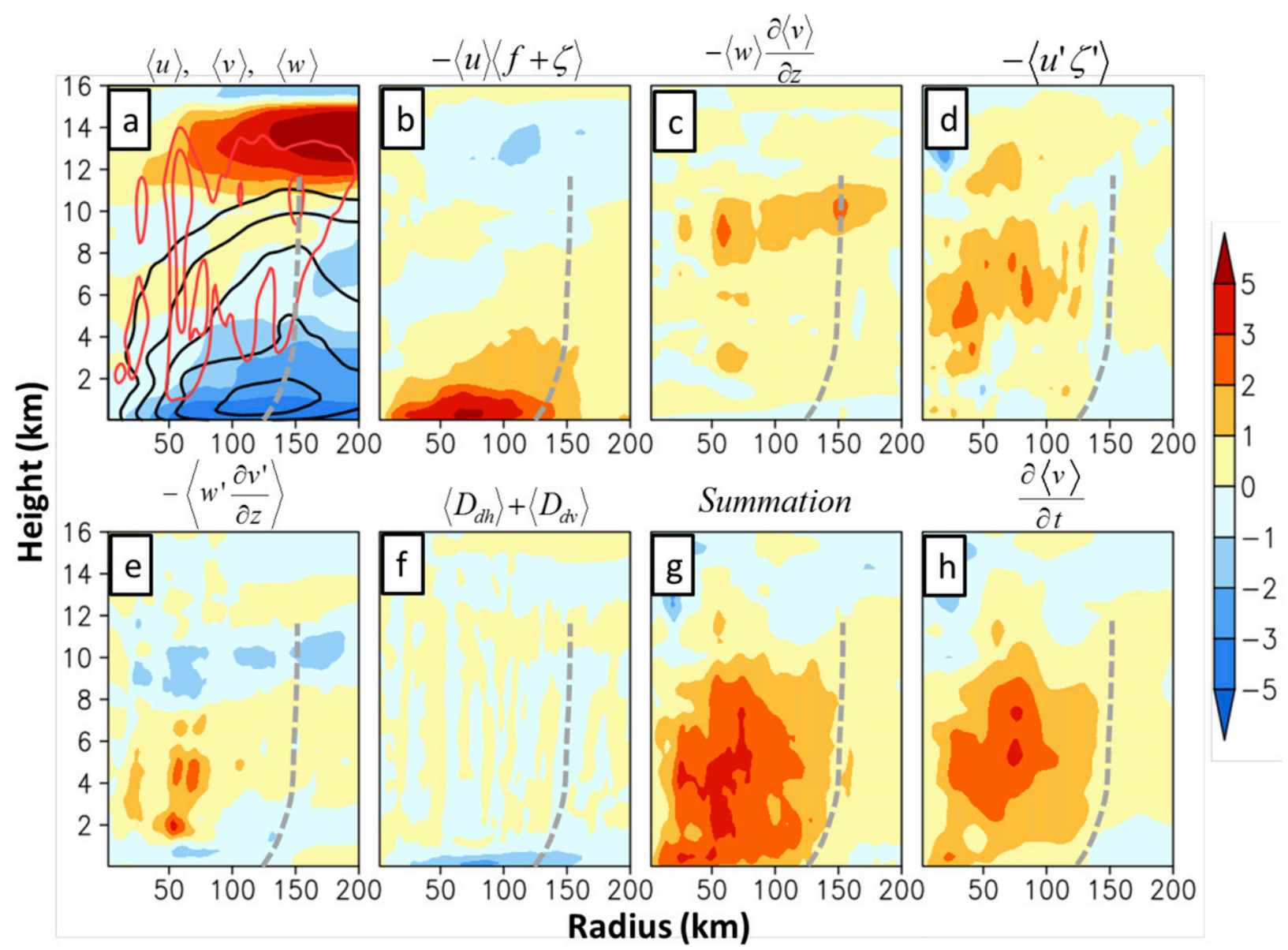

FIG. 8. Radius-height cross sections of azimuthally averaged (a) radial wind (shading), tangential wind (black contour at $3 \mathrm{~m} \mathrm{~s}{ }^{-1}$ interval), and upward motion (red contour at $0.3 \mathrm{~m} \mathrm{~s}^{-1}$ interval); (b) mean absolute vorticity flux; (c) mean vertical advection of tangential wind; (d) radial eddy vorticity flux; (e) eddy vertical advection of tangential wind; (f) horizontal and vertical diffusive tendency; (g) summation of (b)-(f); and (h) tangential wind tendency directly from the model output for the RI member averaged between -3 and $0 \mathrm{~h}$. The unit for (b)-(h) is $\mathrm{m} \mathrm{s}^{-1} \mathrm{~h}^{-1}$. The gray dashed lines denote the RMW.

Second, the radial inflow does not penetrate as far as that of the RI member. Third, the mean vertical motion is narrower yet stronger compared to the RI member. Figure 5 shows that deep convection for the NI member in this 3-h time window is trapped downshear, unlike the deep convection for the RI member that wraps around the storm and spirals inward. Therefore, the time and azimuthal average of vertical motion for the NI member will be more localized in radius and have a stronger mean compared to that of the RI member. The different behavior of deep convection for the NI member and RI member can also explain the less inward penetration of radial inflow in the NI member. The positive contribution in the PBL by the influx of mean vorticity (Fig. 9b) is also observed in the NI case, although the magnitude is slightly smaller than that of the RI member. The comparison of Figs. $8 \mathrm{~g}$ and $9 \mathrm{~g}$ reveals that the major difference between the RI member and the NI member is located between $4-$ and $10-\mathrm{km}$ altitudes and inside the RMW, where the RI member shows a strong positive tendency, yet the NI member shows a slight negative tendency in most of the region. Figures $8 \mathrm{~d}$ and $9 \mathrm{~d}$ show that these differences are caused by the completely different behavior of the radial eddy vorticity flux in the two members, which has a significant positive contribution to the positive tendency in the RI member in the middle to upper levels but tends to spin down the tangential wind in the NI member.

The comparison of the budget analysis between the RI member and the NI member pinpoints the radial eddy vorticity flux as the key term that contributes to the different intensity changes in the two members. However, it cannot explain why the radial eddy vorticity flux behaves so differently in the two members. To further identify the cause of the different behavior of the eddy vorticity flux in the two members, Figs. 10a and 10d show 


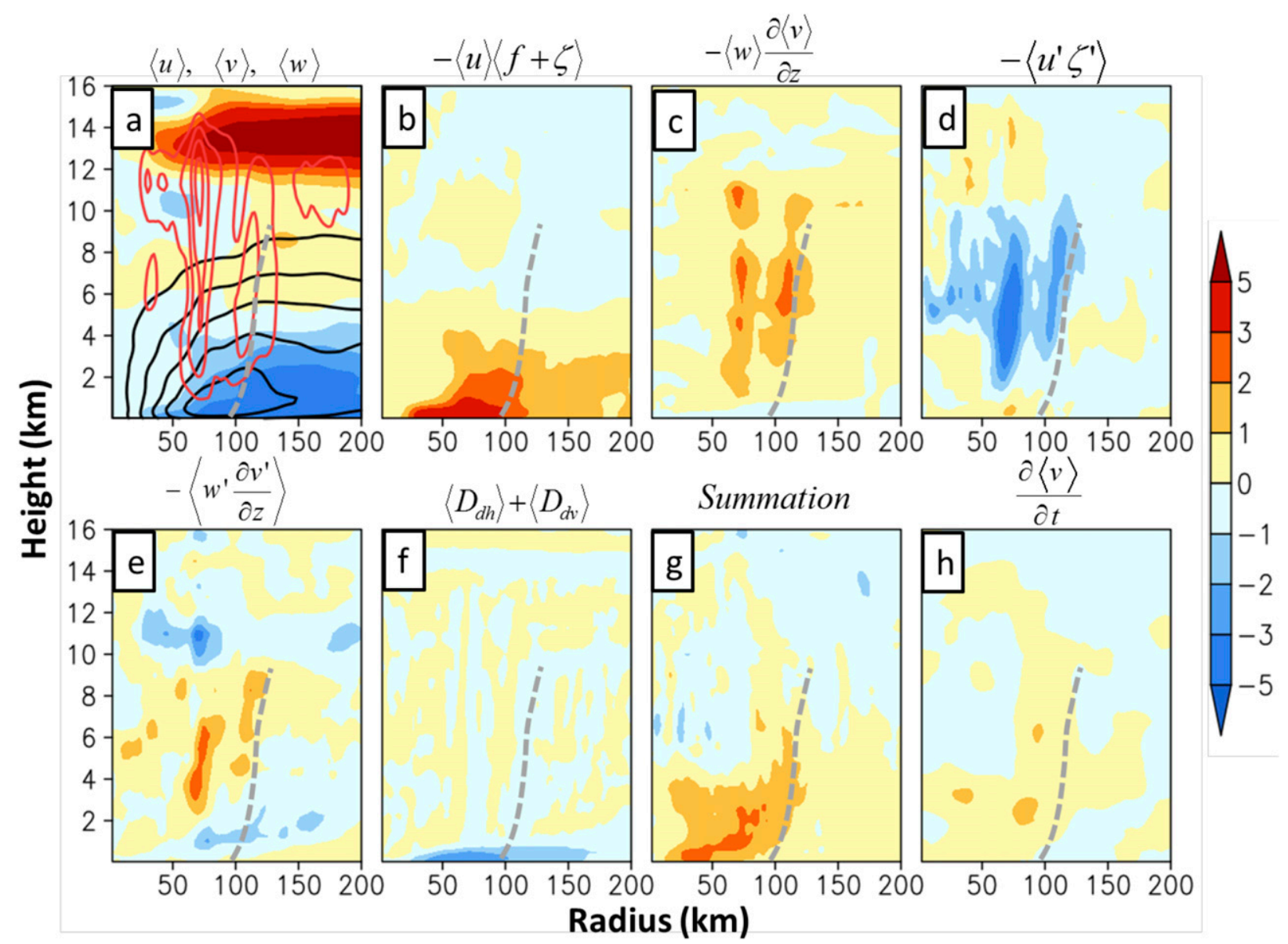

FIG. 9. As in Fig. 8, but for the NI member averaged between -7 and $-4 \mathrm{~h}$.

the horizontal cross section of the radial eddy vorticity flux $\left(-\left\langle u^{\prime} \zeta^{\prime}\right\rangle\right)$ averaged between 6 and $10 \mathrm{~km}$ and -3 and $0 \mathrm{~h}$ for the RI member (Fig. 10a) and -7 and $-4 \mathrm{~h}$ for the NI member (Fig. 10d). As can be seen, the RI member (Fig. 10a) shows a strong positive eddy vorticity flux in the downshear-left quadrant inside the RMW, collocating with the location of deep convection (Figs. 5b,c). In contrast, the NI member (Fig. 10d) shows a strong negative eddy vorticity flux in the downshear/ downshear-right quadrant, also collocated with the location of deep convection (Figs. 5f,g). This raises an interesting question: Why is deep convection associated with a positive eddy vorticity flux in the RI member but with a negative eddy vorticity flux in the NI member?

Equation (1) shows that there are two components of the eddy vorticity flux: eddy radial flow and eddy vorticity. This means the configuration of eddy radial flow and eddy vorticity are both crucial to determining the eddy vorticity flux. Figures $10 \mathrm{~b}$ and $10 \mathrm{e}$ show the eddy vorticity (shading) and eddy radial flow (vector) averaged within $6-10 \mathrm{~km}$ and between -3 and $0 \mathrm{~h}$ for the RI member and between -7 and $-4 \mathrm{~h}$ for the NI member. The eddy radial flow fields are very similar between the RI member and the NI member, with the strongest inflow in the northwestern quadrant. This quadrant covers part of the downshear-left quadrant, part of the upshearleft quadrants, and the strongest outflow in the southeastern quadrant. This eddy radial flow distribution might be closely related to the storm movement, which is northwestward in both the RI and NI members.

It is the eddy vorticity that makes the difference between the RI member and the NI member in the eddy vorticity flux. The eddy vorticity in the RI member shows a large patch of relatively smooth positive vorticity located in the downshear/downshear-left quadrant, most of which is inside the RMW. The negative eddy vorticity areas are mainly located inside the RMW in the upshear hemisphere and outside the RMW in the downshear/downshear-right quadrant. Locations with positive (negative) eddy vorticity collocated with eddy radial inflow (outflow) lead to positive eddy vorticity flux, which explains the eddy vorticity flux pattern 

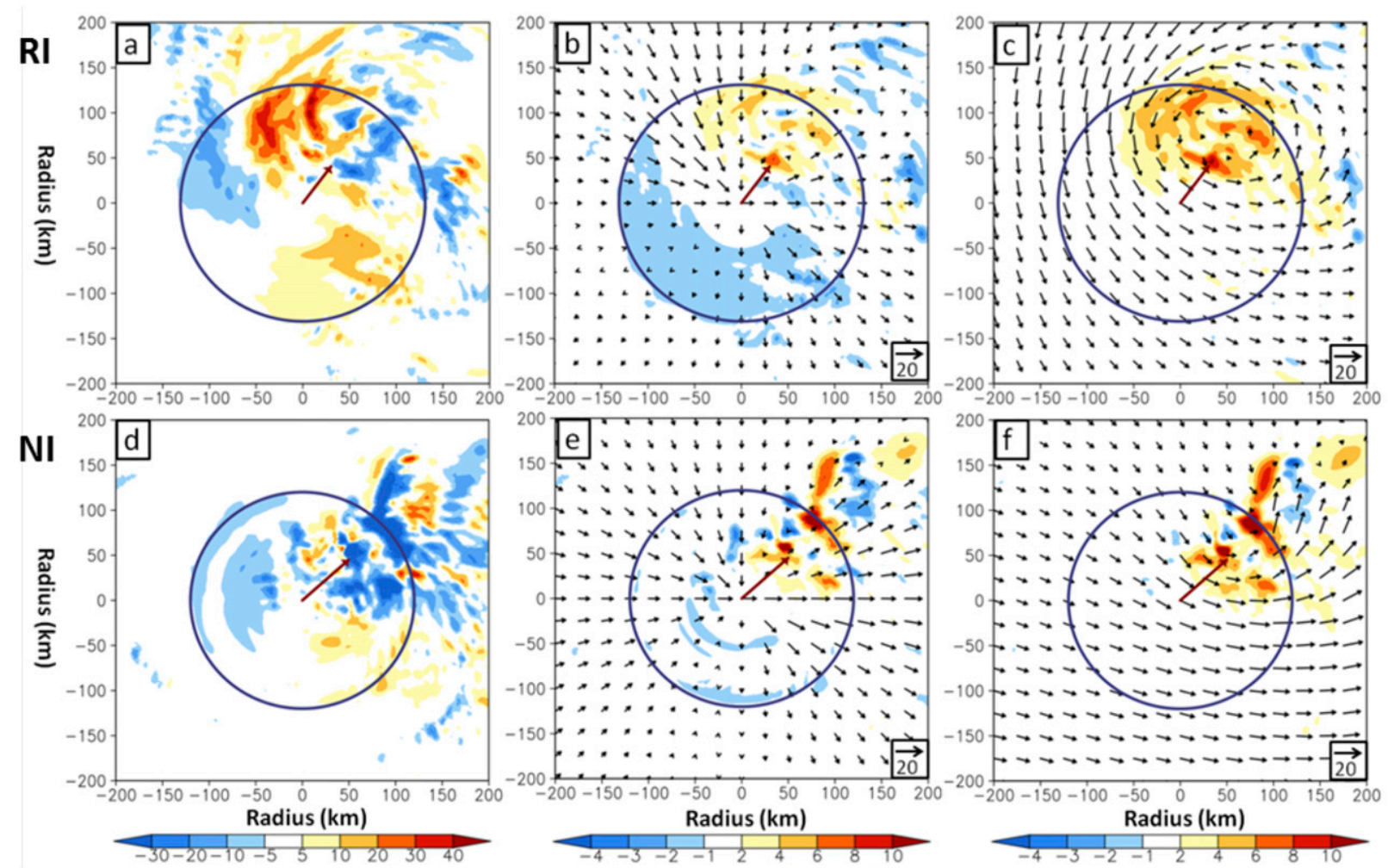

FIG. 10. Horizontal cross sections of (a) eddy radial vorticity flux $\left(\mathrm{m} \mathrm{s}^{-1} \mathrm{~h}^{-1}\right)$, (b) eddy radial component of storm-relative flow (vectors) and eddy vorticity (shading; $10^{-4} \mathrm{~m} \mathrm{~s}^{-2}$ ), (c) storm-relative flow (vectors) and vorticity (shading; $10^{-4} \mathrm{~m} \mathrm{~s}^{-2}$ ) averaged between 6 and $10 \mathrm{~km}$ and -3 and $0 \mathrm{~h}$. (d)-(f) As in (a)-(c), respectively, but for the NI member averaged between -7 and $-4 \mathrm{~h}$. Dark blue circles indicate the RMW, and red arrows denote the shear vector.

observed in Fig. 10a. In contrast, eddy vorticity in the NI member (Fig. 10e), located in the downshear region, shows a dipole pattern with stronger positive vorticity next to weaker negative vorticity. The positive vorticity is mainly located in the downshear/downshear-right quadrant, which is collocated with the radial outflow. The negative vorticity is mainly located in the downshear/downshear-left quadrant, which is collocated with weak radial inflow. This eddy radial floweddy vorticity configuration leads to the negative eddy vorticity flux in the downshear region. The distribution of eddy vorticity in the NI member does not show a clear separation in the radial direction, as seen in the RI member (Fig. 10b). Figures 10c and 10f show the total storm-relative flow field and the total vorticity averaged between 6 and $10 \mathrm{~km}$ and the 3 -h time window. The total vorticity of the RI member (Fig. 10c) shows a similar pattern to the eddy vorticity since deep convection mainly contributes to the vorticity pattern in the downshear-left quadrant.

The storm-relative flow field shows that a closed circulation has developed associated with the deep convection taking place in the downshear/downshear-left quadrant. In contrast to the closed circulation associated with deep convection in the RI member, the stormrelative field in the NI member shows that the circulation associated with downshear deep convection is highly asymmetric, with stronger flow to the south and weaker flow to the north of the deep convection. This implies the storm-relative environmental flow might be westerly in the downshear and opposes the formation of a closed circulation associated with deep convection. The closed circulation in the RI member and unclosed circulation in the NI member might explain the smooth patch of positive vorticity inside the RMW in the RI member and the vorticity dipole structure in the NI member, as Montgomery and Enagonio (1998) showed that positive vorticity moves inward and negative vorticity moves outward during the axisymmetrization process.

The budget calculation of tangential wind tendency was also performed during $0-36 \mathrm{~h}$ for both the RI and NI members (not shown). The budget calculation for the RI member reveals that as the vortex becomes more symmetric and vertically aligned, the radial eddy vorticity flux in the middle to upper levels evolves from positive to negative, and the radial advection of mean vorticity 
becomes the dominant term in the budget equation. The positive contribution of vertical advection from the mean tangential wind is mostly offset by the negative contribution of vertical advection from the eddy tangential wind in the upper level. The budget calculation for the NI members shows that the radial eddy vorticity flux in the middle to upper levels remains negative during $0-36 \mathrm{~h}$, and therefore, the vortex never becomes vertically aligned.

In summary, Fig. $6 \mathrm{~b}$ shows that the intensification of the RI members is associated with the reduction of vortex tilt, and the budget analysis of the tangential momentum implies that the radial eddy vorticity flux might be responsible for the reduction of the tilt. Figure 10 suggests that upper-level environmental flow might play an important role in determining whether the radial eddy vorticity flux helps spin up the tangential wind in the upper level or reduces the vortex tilt.

\section{Environmental factors affecting storm structure and inner-core dynamics}

An early study by Tuleya and Kurihara (1981) proposed that shear direction could impact storm structure and intensity. Their results showed easterly shear is more favorable for storm development than westerly shear for a westward-moving storm. They argued that the coupling between the lower and upper levels of the vortex is more complete in easterly shear since the lower-level and upper-level warm cores are in phase. Although the results of Tuleya and Kurihara (1981) are consistent with observational statistics (Cheung 2004), Nolan and McGauley (2012) argued that the reason easterly shear is more conducive to storm development and intensification in the observations is because easterly shear is often associated with favorable thermodynamic environmental factors. They also questioned the argument that "the lowlevel disturbances propagated westward rather quickly, between 4 and $6 \mathrm{~m} \mathrm{~s}^{-1}$ faster than the low-level flow for easterly shear" (Nolan and McGauley 2012, p. 25), which was crucial for Tuleya and Kurihara's (1981) coupling argument. The results of Nolan and McGauley (2012) showed that westerly shear was more favorable for the development of a westward-moving storm because of enhanced surface fluxes that favor the development of new convection upshear, bringing deep convection closer to the circulation center and reducing the tilt of the system.

To examine if shear direction is associated with storm structure and intensity change in the RI and NI members, Fig. 11 shows a time series of the composite zonal shear and meridional shear for the RI and NI members. It is worthy of mention that all calculations performed in

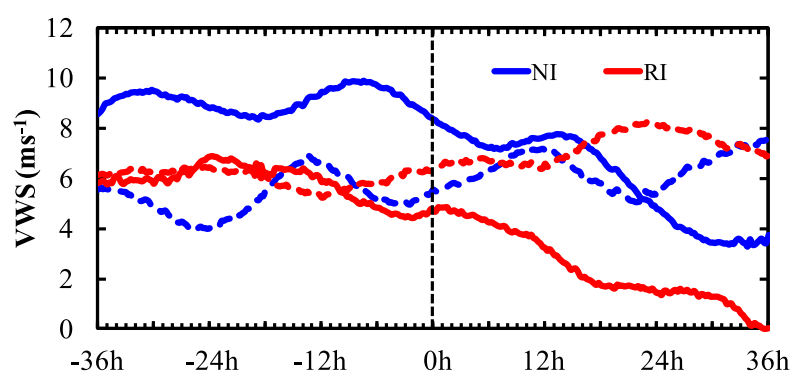

FIG. 11. Time series of composite zonal (solid line) and meridional (dashed line) shear for the RI (red line) and NI (blue line) members.

this section are based on environmental factors with the fields associated with the vortex removed following Kurihara et al. (1993). As observed, meridional shear from the two groups is close to each other and remains southerly at $5-8 \mathrm{~m} \mathrm{~s}^{-1}$ throughout the 72 -h window of interest. The zonal shear shows a much larger difference between the two groups than the meridional shear. The NI group has a more westerly component compared to the RI group. At $-36 \mathrm{~h}$, the westerly zonal shear is $6 \mathrm{~m} \mathrm{~s}^{-1}$ for the RI group, about $3 \mathrm{~m} \mathrm{~s}^{-1}$ weaker than the NI group. It decreases at $-18 \mathrm{~h}$ and reaches $0 \mathrm{~m} \mathrm{~s}^{-1}$ at $36 \mathrm{~h}$. The zonal shear for the NI group decreases at around $-6 \mathrm{~h}$ and reaches $3.5 \mathrm{~m} \mathrm{~s}^{-1}$ at $30 \mathrm{~h}$. The comparison of Figs. 8 and 2 implies that intensity change for the RI group is more tied to zonal shear than to total shear. However, the relationship between zonal shear and intensity change for the NI group is not as clear as that for the RI group. Overall, this result is more consistent with Tuleya and Kurihara's (1981) conclusions.

Upper-level flow impacts zonal shear to a large degree. To examine whether upper-level flow could impact storm structure and intensity in a way that is different from shear perspective, Fig. 12 shows a 3 -h evolution of storm-relative environmental flow at $8-\mathrm{km}$ altitude superposed with environmental relative humidity at the same level within a $2000 \mathrm{~km} \times 2000 \mathrm{~km}$ domain surrounding the storm center for the same RI member (Figs. 12a-d) and the same NI member (Figs. 12e-h) as in Fig. 5. Figures 12i-1 show the difference between the NI and RI members. The time for each panel in Fig. 12 is the same as in Fig. 5. Black circles indicate the RMWs at 2-km altitude, and red arrows depict the shear vectors. For the RI members, the storm-relative environmental flow has a strong cyclonic component in all quadrants except the northeastern quadrant at the starting time (Fig. 12a). Three hours later (Fig. 12b), the stormrelative northerly flow to the north of the storm center weakens, and the overall storm-relative environmental flow is weak around the storm, except for the strong 

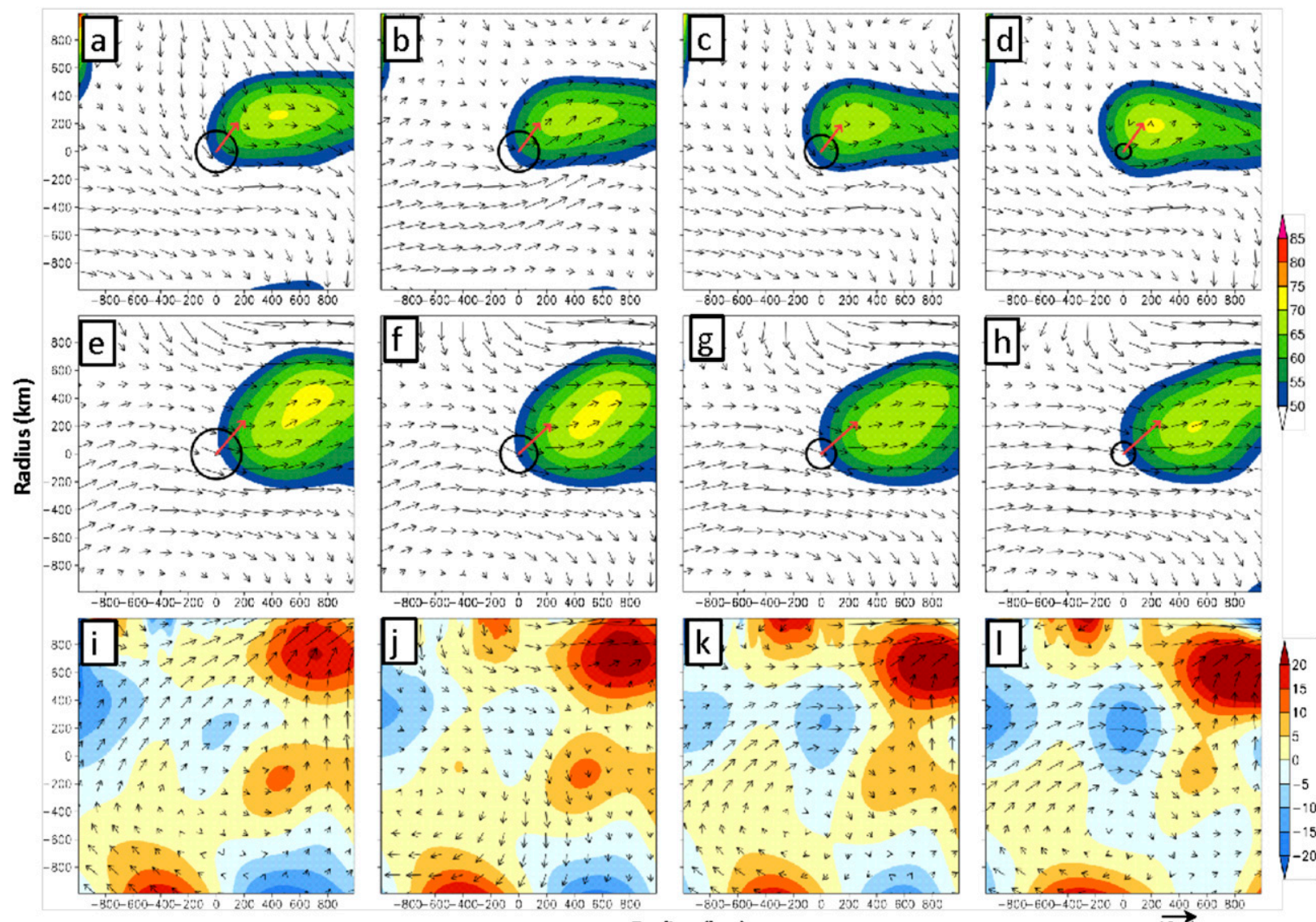

Radius (km)

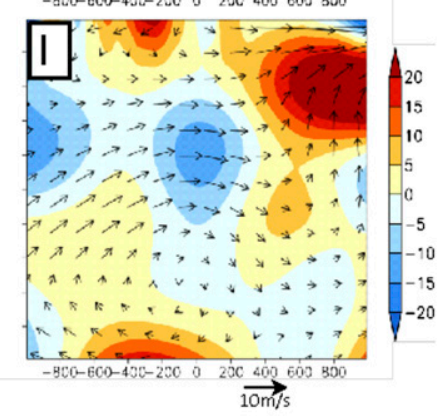

FIG. 12. (a)-(h) As in Fig. 5, but for environmental relative humidity (\%) and storm-relative environmental flow at 8-km altitude. Black circles indicate the RMW at $2 \mathrm{~km}$, and red arrows depict the shear vector. (i)-(l) The difference between the NI and RI (NI - RI) members. The shading shows the relative humidity difference $(\%)$, and vectors show the difference in storm-relative environmental flow at 8-km altitude.

westerly flow to the south of the storm, which aids cyclonic rotation of the vortex.

As deep convection makes its way cyclonically downstream (i.e., the northern quadrants; cf. Figs. $5 \mathrm{c}$ and 5d), storm-relative environmental flow remains weak. This allows the deep convection to continue moving downstream to the left of shear where the radial eddy inflow maximizes (cf. Fig. 10b) and leads to the positive eddy vorticity influx. In contrast, the storm-relative westerly environmental flow for the NI member at the starting time is present in the northern quadrants (Fig. 12e), most of which corresponds to the left-of-shear quadrants. Deep convection is located downshear (i.e., the northeastern quadrant) at this time. Over the next $6 \mathrm{~h}$ (Figs. 12f,g), storm-relative westerly flow in the northern quadrants remains and inhibits the cyclonic propagation of deep convection, keeping it trapped downshear and in the downshearright quadrant. Despite the strong eddy inflow that exists in the left-of-shear region (cf. Fig. 10e), this inflow will not help the influx of positive vorticity since positive vorticity associated with deep convection is trapped downshear. Three hours later, the stormrelative westerly flow in the northern quadrants becomes stronger, and deep convection is sheared farther to the east (Fig. 5i). The evolution of the differences between the NI and RI members can be clearly seen in Figs. 12i-1.

Figures 5, 10, and 12 suggest that upper-level flow might impact storm structure and intensity through a mechanism that is different from the traditional view of the impact of shear. To quantify the role of stormrelative environmental upper-level flow in shearoriented quadrants, we calculated the composite of the tangential component of the storm-relative environmental flow within a 500-km radius in a layer between 6 and $10 \mathrm{~km}$ in the shear-oriented quadrants for the RI group (Fig. 13a) and the NI group (Fig. 13b). The composite maximum azimuthally averaged wind speed at $2-\mathrm{km}$ altitude is also plotted to aid in viewing the 

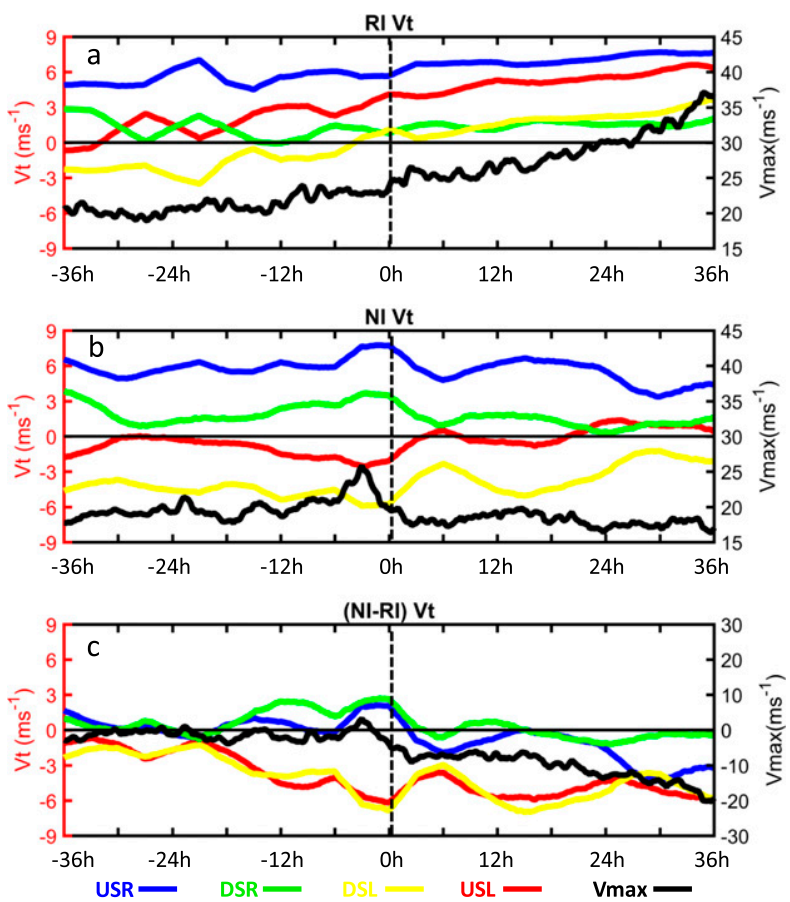

FIG. 13. Time series of the composite tangential component of environmental wind in shear-oriented quadrants averaged between 6- and $10-\mathrm{km}$ altitudes within a 500-km radius for (a) RI members, (b) NI members, and (c) the difference between RI and NI members.

relationship between storm intensity and storm-relative upper-level environmental flow.

For the RI group, storm-relative upper-level environmental flow has a strong cyclonic component in the upshear-right quadrant during the 72-h window of interest, which is due to strong westerly flow to the south of the storm. The anticyclonic component of the storm-relative upper-level environmental flow is present between -36 and $-4 \mathrm{~h}$ in the downshear-left quadrant but decreases with time and becomes cyclonic after $-4 \mathrm{~h}$. For the upshear-left quadrant, stormrelative upper-level environmental flow is slightly anticyclonic with a magnitude close to zero between -36 and $-33 \mathrm{~h}$. It then becomes cyclonic and fluctuates before $-12 \mathrm{~h}$, after which the cyclonic flow continues to increase slowly with time. The storm-relative upperlevel environmental flow changes little in the downshear-right quadrant. Overall, the cyclonic stormrelative upper-level environmental flow increases gradually for the RI group. The evolution of stormrelative environmental flow shown in Figs. 12a-d corresponds to the time window between -6 and $3 \mathrm{~h}$, during which time storm-relative environmental flow left of shear becomes cyclonic.

The storm-relative upper-level environmental flow for the NI group shows an interesting mirror behavior, with weak cyclonic flow in the downshear-right quadrant mirroring weak anticyclonic flow in the upshearleft quadrant and strong cyclonic flow in the upshearright quadrant mirroring strong anticyclonic flow in the downshear-left quadrant. The storm-relative upperlevel environmental flow becomes more cyclonic between -29 and $-2 \mathrm{~h}$ in the right-of-shear quadrants, while it becomes more anticyclonic at the same time in the left-of-shear quadrants. During the time window between -10 and $-1 \mathrm{~h}$ when the evolution of stormrelative environmental flow of the NI member is shown in Figs. $12 \mathrm{e}-\mathrm{h}$, the anticyclonic component of stormrelative upper-level environmental flow is particularly strong in the left-of-shear quadrants. This implies the distribution of storm-relative upper-level environmental flow is more important than the area average of the flow field. When storm-relative upper-level environmental flow is anticyclonic and to the left of shear, it tends to inhibit the cyclonic propagation of deep convection, which tries to wrap around into the upshearleft quadrant through the downshear-left quadrant.

Figure $13 \mathrm{c}$ shows the difference between the tangential component of storm-relative upper-level environmental flow for the NI group and the RI group (NI - RI). Negative values mean the storm-relative upper-level environmental flow in the NI group is more anticyclonic. Although the difference in the storm-relative upper-level environmental flow between the NI group and the RI group in the right-of-shear quadrants is marginal, this difference is much larger for the left-of-shear quadrants, indicating the flow is more anticyclonic in the left-ofshear quadrants for the NI group than for the RI group. Figure 13, which represents the composites for the RI and NI groups, confirms the hypothesis made upon the comparison of a single RI member and NI member that the storm-relative upper-level environmental flow to the left of shear is more important than that of the right of shear since it determines whether deep convection, if it ever occurs, can make its way cyclonically downstream to the upshear-left quadrant and reduce vortex asymmetry and tilt magnitude.

Although the tangential component of the stormrelative upper-level environmental flow might explain the overall behavior of the azimuthal distribution of deep convection and its relation to intensity change in the RI and NI groups, it cannot explain why the intensity of the NI group decreases between 0 and $6 \mathrm{~h}$ when storm-relative upper-level environmental flow in the left-of-shear quadrants becomes less anticyclonic. Of note, environmental flow is only one aspect of the largescale environmental factors. Other environmental factors, such as moisture, could also play an important role in storm structure and intensity change. 

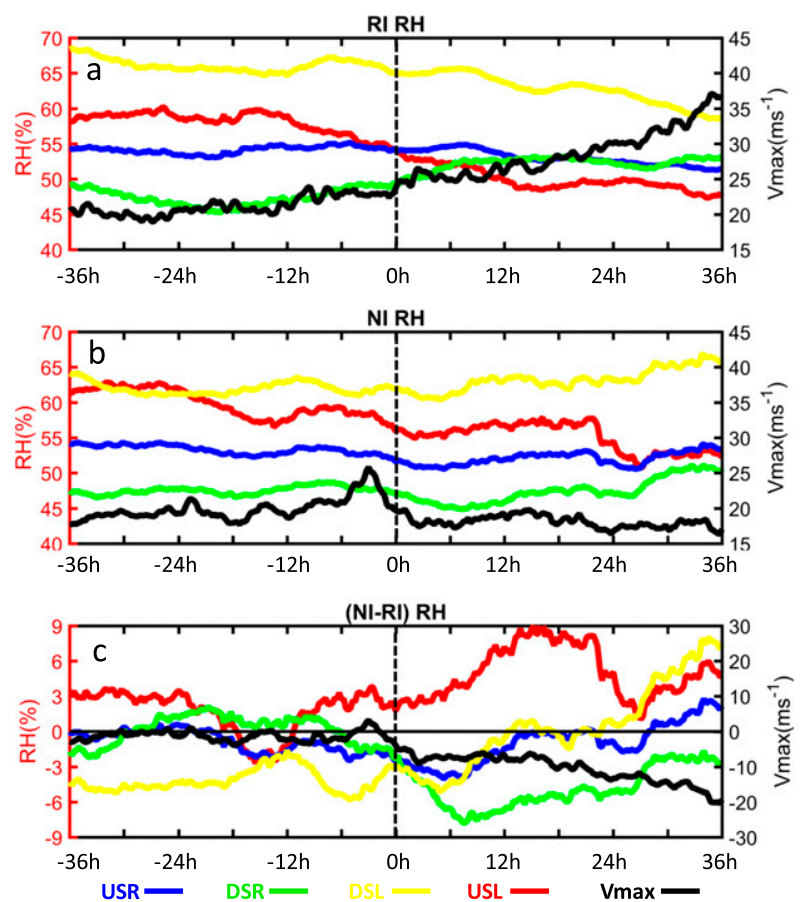

FIG. 14. As in Fig. 13, but for environmental relative humidity averaged between $2-$ and $6-\mathrm{km}$ altitudes.

Figure 14 shows the composite of environmental moisture averaged within a $500-\mathrm{km}$ radius between 2 and 6-km altitude for the RI and NI groups. The environment is the most humid in the downshear-left quadrant throughout the 72-h period of interest for both the RI and NI groups. However, moisture in the other three quadrants evolves differently between the RI group and the NI group. In the RI group, environmental moisture is dry in the downshear-right quadrant between -36 and $-12 \mathrm{~h}$ and slowly increases over the next $18 \mathrm{~h}$. In contrast, the dry environment in the downshear-right quadrant for the NI group remains dry with a slight decrease around $0 \mathrm{~h}$, which is associated with a weakening of the storms. The moisture difference plot (NI - RI) between the two groups (Fig. 14c) shows that the NI group has a drier environment in the downshear quadrants (downshear-left quadrant between -36 and $0 \mathrm{~h}$ and the downshear-right quadrant between 0 and $36 \mathrm{~h}$ ) and a moister environment in the upshear-left quadrant. These results are consistent with recent ensemble studies (Rios-Berrios et al. 2016a,b). Earlier observational studies (Reasor et al. 2013; Zhang et al. 2013) showed that inflow is much deeper in the downshear-right quadrant where deep convection originates. Therefore, environmental moisture in the downshear-right quadrant could play an important role in triggering deep convection, as indicated by Fig. 14.
Both the environmental kinematic field (Fig. 10) and environmental moisture field (Fig. 11) are important for the evolution of storm structure and intensity change. Environmental moisture, especially in the downshearright quadrant, is crucial for the formation of deep convection. Environmental flow, especially in the leftof-shear quadrants, is critical for the cyclonic propagation of deep convection to the upshear-left quadrant and whether the radial eddy vorticity flux will help spin up the tangential wind in the middle to upper levels and reduce vortex tilt.

\section{Summary and conclusions}

In this study, an analysis of forecasts from the operational HWRF ensemble system for Hurricane Edouard (2014) was used to study the differences in both the innercore structure and large-scale environment between RI and NI members. The following are the salient findings:

(i) This study confirms that the downshear-left quadrant is important in terms of the azimuthal location of deep convection. It also reveals that intensity changes are closely related to whether deep convection makes its way into the upshear-left quadrant. As convection wraps around to the upshear-left quadrant from the downshear side of the storm for RI members, vortex tilt and asymmetry reduce rapidly and rapid intensification occurs. For NI members, convection is trapped in the downshear/ downshear-right quadrant, and vortex tilt and asymmetry remain large throughout the 72-h period.

(ii) A budget analysis of tangential momentum reveals that the radial eddy vorticity flux contributes positively to the spinup of tangential winds in the middle to upper levels and reduces vortex tilt in the RI member. In contrast, the negative eddy vorticity flux for the NI member spins down the tangential winds in the middle to upper levels and does not vertically align the vortex. This difference suggests that positive radial eddy vorticity flux is a key process that contributes to intensity change in a sheared environment by spinning up the tangential winds in the middle to upper levels and reducing tilt. As the vortex becomes more symmetric and vertically aligned, the radial advection of mean vorticity becomes the dominant term that contributes to the continuing intensification of the RI member.

(iii) The conventional environmental indices (e.g., SHIPS shear and relative humidity in the low and middle levels) are usually calculated as a mean over a large area and ignore local asymmetries. By decomposing the upper-level storm-relative 
environmental flow field and low- to midlevel moisture field into shear-relative quadrants, the impact and role of the large-scale factors becomes clearer. Environmental moisture, especially in the downshear-right quadrant where CBs originate, is crucial for the formation of deep convection. After persistent CBs develop in the downshear side of the storm, the environmental flow field plays an important role in determining if deep convection makes it to the left-of-shear hemisphere and whether the radial eddy vorticity flux spins up the tangential winds in the middle to upper levels and reduces vortex tilt. The storm-relative upper-level environmental flow shows a cyclonic signature in the left-of-shear quadrants for the RI members, which promotes the downstream cyclonic propagation of deep convection through the left-of-shear quadrants and leads to the positive radial eddy vorticity flux. In contrast, the storm-relative upperlevel environmental flow shows an anticyclonic signature in the left-of-shear quadrants for the NI members, which inhibits the downstream cyclonic propagation of deep convection and hinders the positive radial eddy vorticity flux.

The above results are based on the ensemble forecast of Hurricane Edouard with a focus on investigating the interaction of the inner-core deep convection and environmental flow. In the future, more ensemble studies and case studies will be conducted to examine the conclusions drawn in this study. Further studies are needed to identify the large-scale conditions that set up the configuration favorable for producing positive eddy vorticity flux at middle and upper levels.

Acknowledgments. The authors acknowledge funding from NOAA's Hurricane Forecast Improvement Program (HFIP) and support from NOAA Grant NA14NWS4680028. Thanks are due to Ms. Gail Derr and Mr. Paul Leighton for offering editorial support, Drs. Paul Reasor and Ghassan Alaka, as well as Mr. John Kaplan, for internal reviews, Dr. Da-Lin Zhang for help with the budget calculation, and Dr. Michael Montgomery and two anonymous reviewers for helpful external reviews.

\section{REFERENCES}

Arakawa, A., and W. H. Schubert, 1974: Interaction of a cumulus cloud ensemble with the large-scale environment, part I. J. Atmos. Sci., 31, 674-701, https://doi.org/10.1175/1520-0469(1974)031<0674: IOACCE $>2.0 . \mathrm{CO} ; 2$.

Barnes, G. M., E. J. Zipser, D. Jorgensen, and F. Marks Jr., 1983: Mesoscale and convective structure of a hurricane rain- band. J. Atmos. Sci., 40, 2125-2137, https://doi.org/10.1175/ 1520-0469(1983)040<2125:MACSOA > 2.0.CO;2.

Bryan, G. H., R. Rotunno, and Y. Chen, 2010: The effects of turbulence on hurricane intensity. 29th Conf. on Hurricanes and Tropical Meteorology, Tucson, AZ, Amer. Meteor. Soc., 8C.7, https://ams.confex.com/ams/29Hurricanes/techprogram/ paper_167282.htm.

Chen, H., and S. G. Gopalakrishnan, 2015: A study on the asymmetric rapid intensification of Hurricane Earl (2010) using the HWRF system. J. Atmos. Sci., 72, 531-550, https://doi.org/ 10.1175/JAS-D-14-0097.1.

—, D.-L. Zhang, J. Carton, and R. Atlas, 2011: On the rapid intensification of Hurricane Wilma (2005). Part I: Model prediction and structural changes. Wea. Forecasting, 26, 885901, https://doi.org/10.1175/WAF-D-11-00001.1.

Cheung, K. K. W., 2004: Large-scale environmental parameters associated with tropical cyclone formations in the western North Pacific. J. Climate, 17, 466-484, https://doi.org/10.1175/ 1520-0442(2004)017<0466:LEPAWT>2.0.CO;2.

DeMaria, M., 1996: The effect of vertical shear on tropical cyclone intensity change. J. Atmos. Sci., 53, 2076-2087, https://doi.org/ 10.1175/1520-0469(1996)053<2076:TEOVSO > 2.0.CO;2.

_ maximum intensity of Atlantic tropical cyclones. J. Climate, $\mathbf{7}$, 1324-1334, https://doi.org/10.1175/1520-0442(1994)007<1324: SSTATM $>2.0 . \mathrm{CO} ; 2$.

$\longrightarrow$, and - 1994b: A Statistical Hurricane Intensity Prediction Scheme (SHIPS) for the Atlantic basin. Wea. Forecasting, 9, 209-220, https://doi.org/10.1175/1520-0434(1994)009<0209: ASHIPS $>2.0 . \mathrm{CO} ; 2$.

Ek, M. B., K. E. Mitchell, Y. Lin, E. Rogers, P. Grunmann, V. Koren, G. Gayno, and J. D. Tarpley, 2003: Implementation of Noah land surface model advancements in the National Centers for Environmental Prediction operational mesoscale Eta model. J. Geophys. Res., 108, 8851, https://doi.org/10.1029/ 2002JD003296.

Ferrier, B. S., 2005: An efficient mixed-phase cloud precipitation scheme for use in operational NWP models. Eos, Trans. Amer. Geophys. Union, 86 (Joint Assembly Suppl.), Abstract A42A-02.

Finocchio, P. M., S. J. Majumdar, D. S. Nolan, and M. Iskandarani, 2016: Idealized tropical cyclone responses to the height and depth of environmental vertical wind shear. Mon. Wea. Rev., 144, 2155-2175, https://doi.org/10.1175/ MWR-D-15-0320.1.

Frank, W. M., and E. A. Ritchie, 1999: Effects of environmental flow upon tropical cyclone structure. Mon. Wea. Rev., 127, 2044-2061, https://doi.org/10.1175/1520-0493(1999)127<2044: EOEFUT $>2.0 . \mathrm{CO} ; 2$.

— tensity and structure of numerically simulated hurricanes. Mon. Wea. Rev., 129, 2249-2269, https://doi.org/10.1175/ 1520-0493(2001)129<2249:EOVWSO>2.0.CO;2.

Gopalakrishnan, S. G., F. Marks, X. Zhang, J.-W. Bao, K.-S. Yeh, and R. Atlas, 2011: The experimental HWRF system: A study on the influence of horizontal resolution on the structure and intensity changes in tropical cyclones using an idealized framework. Mon. Wea. Rev., 139, 1762-1784, https://doi.org/ 10.1175/2010MWR3535.1.

_ , and Coauthors, 2012: Hurricane Weather Research and Forecasting (HWRF) Model: 2012 scientific documentation. HWRF Development Testbed Center Tech. Rep., 96 pp., https://dtcenter.org/HurrWRF/users/docs/scientific_documents/ HWRFScientificDocumentation_v3.4a.pdf. 
F. Marks, J. A. Zhang, X. Zhang, J.-W. Bao, and V. Tallapragada, 2013: A study of the impacts of vertical diffusion on the structure and intensity of tropical cyclones using the high-resolution HWRF system. J. Atmos. Sci., 70, 524-541, https://doi.org/10.1175/JAS-D-11-0340.1.

— C. V. Srinavas, and K. Bhatia, 2016: The hurricane boundary layer. Advanced Numerical Modeling and Data Assimilation Techniques for Tropical Cyclone Predictions, U. C. Mohanty and S. G. Gopalakrishnan, Eds., Springer Netherlands, 589626, https://doi.org/10.5822/978-94-024-0896-6.

Gray, W. M., 1968: Global view of the origin of tropical disturbances and storms. Mon. Wea. Rev., 96, 669-700, https://doi.org/10.1175/ 1520-0493(1968)096<0669:GVOTOO>2.0.CO;2.

Grell, G. A., 1993: Prognostic evaluation of assumptions used by cumulus parameterizations. Mon. Wea. Rev., 121, 764-787, https:// doi.org/10.1175/1520-0493(1993)121<0764:PEOAUB >2.0.CO;2.

Hong, S.-Y., and H.-L. Pan, 1996: Nonlocal boundary layer vertical diffusion in a medium-range forecast model. Mon. Wea. Rev., 124, 2322-2339, https://doi.org/10.1175/1520-0493(1996)124<2322: NBLVDI $>2.0 . C O ; 2$.

Hoskins, B. J., M. E. McIntyre, and A. W. Robertson, 1985: On the use and significance of isentropic potential vorticity maps. Quart. J. Roy. Meteor. Soc., 111, 877-946, https://doi.org/ 10.1002/qj.49711147002.

Iacono, M. J., J. S. Delamere, E. J. Mlawer, M. W. Shephard, S. A. Clough, and W. D. Collins, 2008: Radiative forcing by longlived greenhouse gases: Calculations with the AER radiative transfer models. J. Geophys. Res., 113, D13103, https://doi.org/ 10.1029/2008JD009944.

Jones, S. C., 1995: The evolution of vortices in vertical shear. I: Initially barotropic vortices. Quart. J. Roy. Meteor. Soc., 121, 821-851, https://doi.org/10.1002/qj.49712152406.

Kaplan, J., and M. DeMaria, 2003: Large-scale characteristics of rapidly intensifying tropical cyclones in the North Atlantic basin. Wea. Forecasting, 18, 1093-1108, https://doi.org/ 10.1175/1520-0434(2003)018<1093:LCORIT>2.0.CO;2.

,-- , and J. A. Knaff, 2010: A revised tropical cyclone rapid intensification index for the Atlantic and eastern North Pacific basins. Wea. Forecasting, 25, 220-241, https://doi.org/10.1175/ 2009WAF2222280.1.

_- and Coauthors, 2015: Evaluating environmental impacts on tropical cyclone rapid intensification predictability utilizing statistical models. Wea. Forecasting, 30, 1374-1396, https://doi.org/ 10.1175/WAF-D-15-0032.1.

Koren, V., J. Schaake, K. Mitchell, Q.-Y. Duan, and F. Chen, 1999: A parameterization of snowpack and frozen ground intended for NCEP weather and climate models. J. Geophys. Res., 104, 19569-19585, https://doi.org/10.1029/1999JD900232.

Kurihara, Y., M. A. Bender, and R. J. Ross, 1993: An initialization scheme of hurricane models by vortex specification. Mon. Wea. Rev., 121, 2030-2045, https://doi.org/10.1175/ 1520-0493(1993)121<2030:AISOHM>2.0.CO;2.

Kwon, Y. C., S. Lord, B. Lapenta, V. Tallapragada, Q. Liu, and Z. Zhang, 2010: Sensitivity of air-sea exchange coefficients (Cd and Ch) on hurricane intensity. 29th Conf. on Hurricanes and Tropical Meteorology, Tucson, AZ, Amer. Meteor. Soc., 13C.1, https://ams.confex.com/ams/29Hurricanes/techprogram/ paper_167760.htm.

Liu, Q., N. Surgi, S. Lord, W.-S. Wu, D. Parrish, S. Gopalakrishnan, J. Waldrop, and J. Gamache, 2006: Hurricane initialization in HWRF model. 27th Conf. on Hurricanes and Tropical Meteorology, Monterey, CA, Amer. Meteor. Soc., 8A.2, https://ams.confex.com/ ams/27Hurricanes/techprogram/paper_108496.htm.
Merrill, R. T., 1988: Environmental influences on hurricane intensification. J. Atmos. Sci., 45, 1678-1687, https://doi.org/ 10.1175/1520-0469(1988)045<1678:EIOHI>2.0.CO;2.

Molinari, J., and D. Vollaro, 2010: Rapid intensification of a sheared tropical storm. Mon. Wea. Rev., 138, 3869-3885, https://doi.org/10.1175/2010MWR3378.1.

— , P. Dodge, D. Vollaro, K. L. Corbosiero, and F. Marks Jr., 2006: Mesoscale aspects of the downshear reformation of a tropical cyclone. J. Atmos. Sci., 63, 341-354, https://doi.org/ 10.1175/JAS3591.1.

Montgomery, M. T., and J. Enagonio, 1998: Tropical cyclogenesis via convectively forced vortex Rossby waves in a threedimensional quasigeostrophic model. J. Atmos. Sci., 55, 3176-3207, https://doi.org/10.1175/1520-0469(1998)055<3176: TCVCFV $>2.0 . C O ; 2$.

— tensification. Aust. Meteor. Oceanogr. J., 64, 37-66, https://doi.org/ 10.22499/2.6401.005.

Munsell, E. B., F. Zhang, and D. P. Stern, 2013: Predictability and dynamics of a nonintensifying tropical storm: Erika (2009). J. Atmos. Sci., 70, 2505-2524, https://doi.org/10.1175/ JAS-D-12-0243.1.

Nguyen, L., and J. Molinari, 2015: Simulation of the downshear reformation of a tropical cyclone. J. Atmos. Sci., 72, 45294551, https://doi.org/10.1175/JAS-D-15-0036.1.

Nguyen, M. C., M. J. Reeder, N. E. Davidson, R. K. Smith, and M. T. Montgomery, 2011: Inner-core vacillation cycles during the intensification of Hurricane Katrina. Quart. J. Roy. Meteor. Soc., 137, 829-844, https://oi.org/10.1002/qj.823.

Nolan, D. S., 2011: Evaluating environmental favorableness for tropical cyclone development with the method of point downscaling. J. Adv. Model. Earth Syst., 3, M08001, https://doi.org/ 10.1029/2011MS000063.

_- , and M. G. McGauley, 2012: Tropical cyclogenesis in wind shear: Climatological relationships and physical processes. Cyclones: Formation, Triggers, and Control, $\mathrm{K}$. Oouchi and H. Fudeyasu, Eds., Nova Science Publishers, $1-36$.

— Y. Yoon, and D. P. Stern, 2007: Tropical cyclone intensification from asymmetric convection: Energetics and efficiency. J. Atmos. Sci., 64, 3377-3405, https://doi.org/10.1175/ JAS3988.1.

Onderlinde, M. J., and D. S. Nolan, 2014: Environmental helicity and its effects on development and intensification of tropical cyclones. J. Atmos. Sci., 71, 4308-4320, https://doi.org/10.1175/ JAS-D-14-0085.1.

- , and ——, 2016: Tropical cyclone-relative environmental helicity and the pathways to intensification in shear. J. Atmos. Sci., 73, 869-890, https://doi.org/ 10.1175/J AS-D-15-0261.1.

Ooyama, K. V., 1969: Numerical simulation of the life cycle of tropical cyclones. J. Atmos. Sci., 26, 3-40, https://doi.org/ 10.1175/1520-0469(1969)026<0003:NSOTLC >2.0.CO;2.

_ 1982: Conceptual evolution of the theory and modeling of the tropical cyclone. J. Meteor. Soc. Japan, 60, 369-380, https://doi.org/ 10.2151/jmsj1965.60.1_369.

Persing, J., M. T. Montgomery, J. McWilliams, and R. K. Smith, 2013: Asymmetric and axisymmetric dynamics of tropical cyclones. Atmos. Chem. Phys., 13, 12 299-12 341, https://doi.org/ 10.5194/acp-13-12299-2013.

Powell, M. D., P. J. Vickery, and T. A. Reinhold, 2003: Reduced drag coefficient for high wind speeds in tropical cyclones. Nature, 422, 279-283, https://doi.org/10.1038/nature01481. 
Qin, N., D.-L. Zhang, and Y. Li, 2016: A statistical analysis of steady eyewall sizes associated with rapidly intensifying hurricanes. Wea. Forecasting, 31, 737-742, https://doi.org/10.1175/WAF-D-16-0016.1.

Reasor, P., M. T. Montgomery, and L. D. Grasso, 2004: A new look at the problem of tropical cyclones in vertical shear flow: Vortex resiliency. J. Atmos. Sci., 61, 3-22, https://doi.org/ 10.1175/1520-0469(2004)061<0003:ANLATP > 2.0.CO;2.

_ Hurricane Guillermo (1997). Part I: Low-wavenumber structure and evolution. Mon. Wea. Rev., 137, 603-631, https://doi.org/ 10.1175/2008MWR2487.1.

_ _ R. Rogers, and S. Lorsolo, 2013: Environmental flow impacts on tropical cyclone structure diagnosed from airborne Doppler radar composites. Mon. Wea. Rev., 141, 2949-2969, https:// doi.org/10.1175/MWR-D-12-00334.1.

Riemer, M., M. T. Montgomery, and M. E. Nicholls, 2010: A new paradigm for intensity modification of tropical cyclones: Thermodynamic impact of vertical wind shear on the inflow layer. Atmos. Chem. Phys., 10, 3163-3188, https://doi.org/ 10.5194/acp-10-3163-2010.

Rios-Berrios, R., R. D. Torn, and C. Davis, 2016a: An ensemble approach to investigate tropical cyclone intensification in sheared environments. Part I: Katia (2011). J. Atmos. Sci., 73, 71-93, https://doi.org/10.1175/JAS-D-15-0052.1.

$\longrightarrow, \ldots$, and 2016b: An ensemble approach to investigate tropical cyclone intensification in sheared environments. Part II: Ophelia (2011). J. Atmos. Sci., 73, 1555-1575, https://doi.org/ 10.1175/JAS-D-15-0245.1.

Rogers, R. F., P. Reasor, and S. Lorsolo, 2013: Airborne Doppler observations of the inner-core structural differences between intensifying and steady-state tropical cyclones. Mon. Wea. Rev., 141, 2970-2991, https://doi.org/10.1175/MWR-D-12-00357.1.

_ , J. A. Zhang, J. Zawislak, H. Jiang, G. R. Alvey, E. J. Zipser, and S. N. Stevenson, 2016: Observations of the structure and evolution of Hurricane Edouard (2014) during intensity change. Part II: Kinematic structure and the distribution of deep convection. Mon. Wea. Rev., 144, 3355-3376, https://doi.org/ 10.1175/MWR-D-16-0017.1.

Schubert, W. H., and J. J. Hack, 1982: Inertial stability and tropical cyclone development. J. Atmos. Sci., 39, 1687-1697, https://doi.org/ 10.1175/1520-0469(1982)039<1687:ISATCD > 2.0.CO;2.

Smith, R. K., and M. T. Montgomery, 2016: The efficiency of diabatic heating and tropical cyclone intensification. Quart. J. Roy. Meteor. Soc., 142, 2081-2086, https://doi.org/10.1002/qj.2804.

_ J. A. Zhang, and M. T. Montgomery, 2017: The dynamics of intensification in a Hurricane Weather Research and Forecasting simulation of Hurricane Earl (2010). Quart. J. Roy. Meteor. Soc., 143, 293-308, https://doi.org/10.1002/qj.2922.

Stewart, S. R., 2014: Tropical cyclone report on Hurricane Edouard (AL062014). National Hurricane Center Rep., 19 pp., http:// www.nhc.noaa.gov/data/tcr/AL062014_Edouard.pdf.

Tallapragada, V., C. Kieu, Y. Kwon, S. Trahan, Q. Liu, Z. Zhang, and I.-H. Kwon, 2014: Evaluation of storm structure from the operational HWRF during 2012 implementation. Mon. Wea. Rev., 142, 4308-4325, https://doi.org/10.1175/MWR-D-13-00010.1.

Tang, B., and K. Emanuel, 2010: Midlevel ventilation's constraint on tropical cyclone intensity. J. Atmos. Sci., 67, 1817-1830, https://doi.org/10.1175/2010JAS3318.1.

Tao, C., and H. Jiang, 2015: Distributions of shallow to very deep precipitation-convection in rapidly intensifying tropical cyclones. J. Climate, 28, 8791-8824, https://doi.org/10.1175/ JCLI-D-14-00448.1.
Tao, D., and F. Zhang, 2014: Effect of environmental shear, seasurface temperature and ambient moisture on the formation and predictability of tropical cyclones: An ensemble-mean perspective. J. Adv. Model. Earth Syst., 6, 384-404, https://doi.org/ 10.1002/2014MS000314.

Troen, I., and L. Mahrt, 1986: A simple model of the atmospheric boundary layer: Sensitivity to surface evaporation. Bound.-Layer Meteor., 37, 129-148, https://doi.org/10.1007/BF00122760.

Tuleya, R. E., and Y. Kurihara, 1981: A numerical study on the effects of environmental flow on tropical storm genesis. Mon. Wea. Rev., 109, 2487-2506, https://doi.org/10.1175/1520-0493(1981)109<2487: ANSOTE $>2.0 . \mathrm{CO} ; 2$.

Vigh, J. L., and W. H. Schubert, 2009: Rapid development of the tropical cyclone warm core. J. Atmos. Sci., 66, 3335-3350, https://doi.org/10.1175/2009JAS3092.1.

Wang, Y., 2009: How do outer spiral rainbands affect tropical cyclone structure and intensity? J. Atmos. Sci., 66, 1250-1273, https://doi.org/10.1175/2008JAS2737.1.

Wei, M., T. Zoltan, R. Wobus, Y. Zhu, and C. H. Bishop, 2008: Initial perturbations based on the ensemble transform (ET) technique in the NCEP global operational forecast system. Tellus, $\mathbf{6 0 A}$, 62-79, https://doi.org/10.1111/j.1600-0870.2007.00273.x.

Yablonsky, R. M., and I. Ginis, 2008: Improving the ocean initialization of coupled hurricane-ocean models using feature-based data assimilation. Mon. Wea. Rev., 136, 2592-2607, https://doi.org/ 10.1175/2007MWR2166.1.

Yang, B., Y. Wang, and B. Wang, 2007: The effect of internally generated inner-core asymmetries on tropical cyclone potential intensity. J. Atmos. Sci., 64, 1165-1188, https://doi.org/10.1175/ JAS3971.1.

Zawislak, J. G., H. Jiang, G. R. Alvey, E. J. Zipser, R. F. Rogers, J. A. Zhang, and S. N. Stevenson, 2016: Observations of the structure and evolution of Hurricane Edouard (2014) during intensity change. Part I: Relationship between the thermodynamic structure and precipitation. Mon. Wea. Rev., 144, 3333-3354, https://doi.org/10.1175/ MWR-D-16-0018.1.

Zehr, R. M., 1992: Tropical cyclogenesis in the western North Pacific. NOAA Tech. Rep. NESDIS 61, 181 pp.

Zhang, F., and D. Tao, 2013: Effects of vertical wind shear on the predictability of tropical cyclones. J. Atmos. Sci., 70, 975-983, https://doi.org/10.1175/JAS-D-12-0133.1.

Zhang, J. A., R. F. Rogers, P. D. Reasor, E. W. Uhlhorn, and F. D. Marks, 2013: Asymmetric hurricane boundary layer structure from dropsonde composites in relation to the environmental vertical wind shear. Mon. Wea. Rev., 141, 3968-3984, https:// doi.org/10.1175/MWR-D-12-00335.1.

— D. S. Nolan, R. F. Rogers, and V. Tallapragada, 2015: Evaluating the impact of improvements in the boundary layer parameterization on hurricane intensity and structure forecasts in HWRF. Mon. Wea. Rev., 143, 3136-3155, https://doi.org/ 10.1175/MWR-D-14-00339.1.

— R. F. Rogers, and V. Tallapragada, 2017: Impact of parameterized boundary layer structure on tropical cyclone rapid intensification forecasts in HWRF. Mon. Wea. Rev., 145, 14131426, https://doi.org/10.1175/MWR-D-16-0129.1.

Zhang, Z., V. Tallapragada, C. Kieu, S. Trahan, and W. Wang, 2014: HWRF based ensemble prediction system using perturbations from GEFS and stochastic convective trigger function. Trop. Cyclone Res. Rev., 3, 145-161, https://doi.org/ 10.6057/2014TCRR03.02. 